\title{
Hydrazones in anion transporters: The detrimental effect of a second binding site
}

\author{
Luis Martínez-Crespo, ${ }^{a}$ Lau Halgreen, ${ }^{a}$ Márcio Soares, ${ }^{b}$ Igor Marques, ${ }^{b}$ Vítor Félix, ${ }^{b *}$ Hennie \\ Valkenier $^{a *}$ \\ a. Université Libre de Bruxelles (ULB), Engineering of Molecular NanoSystems, Ecole Polytechnique de Bruxelles, Avenue F.D. \\ Roosevelt 50, CP165/64, B-1050 Brussels, Belgium. hennie.valkenier@ulb.be \\ b. CICECO - Aveiro Institute of Materials, Department of Chemistry, University of Aveiro, 3810-193, Aveiro, Portugal. \\ vitor.felix@ua.pt
}

\section{Abstract}

Synthetic anion transporters can be developed using anion receptors that are able to bind the anion and stabilize it in the lipophilic interior of a bilayer membrane, and they usually contain functional groups with acidic NHs, such as ureas, thioureas and squaramides. To assess the suitability of acylhydrazones as a new functional group for the preparation of anion transporters, we have studied a family of thioureas functionalized with these and related functional groups. ${ }^{1} \mathrm{H}$ NMR titrations and DFT calculations indicate that the thioureas bearing acylhydrazone groups behave as chloride receptors with two separate binding sites, of which the acylhydrazone binds weaker than the thiourea. Chloride transport studies show that the additional binding site has a detrimental effect on thiourea-based transporters, and this phenomenon is also observed for bis(thio)ureas with two separate binding sites. We propose that the presence of a second anion binding unit hinders the transport activity of the thiourea due to additional interactions with the phospholipids of the membrane. In agreement with this hypothesis, extensive molecular dynamics simulations suggest that the molecules will tend to be positioned in the water/lipid interface, driven by the interaction of the NHs of the thiourea and of the acylhydrazone groups with the POPC polar head groups and water molecules. Moreover, the interaction energies show that the poorest transporters have indeed the strongest interactions with the membrane phospholipids, inhibiting chloride transport. This detrimental effect of additional functional groups on transport activity should be considered when designing new ion transporters, unless these groups cooperatively promote anion recognition and transmembrane transport.

\section{Introduction}

An essential function of many proteins embedded in cell membranes is the transport of ions from one side of the membrane to the other side. ${ }^{1}$ Such function helps to maintain homeostasis in cells, and malfunctioning of natural transporters can be the cause of several diseases called channelopathies. ${ }^{2}$ The development of synthetic compounds able to transport ions through lipidic membranes is of high interest, since it could lead to new therapies for the treatment of channelopathies (e.g., Cystic Fibrosis), as well as other diseases such as cancer. ${ }^{3,4}$

Many studies on synthetic ion transporters have contributed to understanding the main structural properties that determine the activity of artificial transporters. Most artificial transporters act either as transmembrane channels or as mobile carriers. ${ }^{5}$ On the one hand, channels are tubular structures that span the membrane and permit the movement of ions through them. On the other hand, mobile carriers are compounds that extract the ion at one side of the membrane, facilitate its diffusion through the lipophilic interior of the bilayer and release it at the other side. Normally, the ion is extracted into the membrane by formation of a complex with the transporter, so a common 
strategy to obtain efficient mobile carriers is to develop good ion receptors. For example, urea-, thiourea- and squaramide-based receptors are efficient chloride transporters because they have two polar NH units able to bind the anion. ${ }^{6}$ Moreover, the transporters must be lipophilic enough to stay in the membrane and produce anion-transporter complexes able to diffuse through the hydrophobic interior. ${ }^{7-9}$ Some of the more efficient mobile carriers contain several urea or thiourea units preorganized in rigid structures to bind a single anion, giving very stable 1:1 complexes. ${ }^{10-12}$ In addition, other groups with acidic $\mathrm{NH}$, such as pyrrole and indole rings, amides, sulphonamides, protonated imines, or $\mathrm{C}-\mathrm{H}$ units from benzo[ $b]$ thiophenes have been combined to obtain efficient transporters with multiple groups able to bind the anion. ${ }^{13-18}$

Acylhydrazones are especially interesting for the development of structurally complex anion receptors, because they have polar $\mathrm{NH}$ groups that can coordinate anions and they can be obtained from dynamic combinatorial libraries (DCL). ${ }^{19-21}$ Moreover, hydrazones can present interesting properties as molecular tools that permit conformational control with light or metalation. ${ }^{22-24} \mathrm{~A}$ family of phenylthiosemicarbazones, that share structural similarities with acylhydrazones and thioureas, has been reported as $\mathrm{pH}$ dependent chloride transporters. ${ }^{25}$ Since protonation of the thiosemicarbazone group was required for those compounds to bind and transport the anion efficiently, this functional group would have limited interest for the development of more complex transporters with multiple dynamic bonds. To the best of our knowledge, the only report of acylhydrazone-based ion transporters describes tripodal acylhydrazones decorated with crownether moieties that self-assemble in the membrane to form photo-sensitive cation channels. ${ }^{26}$ Thus, these functional groups have never been used for the development of anion carriers.

In this work we present a family of monothioureas (1-6, Scheme 1) functionalized with various hydrazones, as well as with other related functional groups, such as ester, aldehyde and acetal groups. We have compared their chloride binding and transport properties and we have observed that phenyl- and acylhydrazones cause an unexpected detrimental effect on the transport properties of the thiourea motif. Our studies suggest that those groups lead to stronger interactions with the membrane and therefore hinder the transport process. Moreover, additional transport studies with compounds 16-19 indicated that low transport activity is a general feature of urea and thiourea-based transporters with multiple binding units that cannot bind the same anion.

Scheme 1 Structures of the monothioureas studied in this work.<smiles>[R2]c1ccc(NC(=S)Nc2cc(C(F)(F)F)cc(C(F)(F)F)c2)cc1[R2]</smiles>

$1 \mathrm{R}_{1}=\mathrm{H} ; \mathrm{R}_{2}=\mathrm{H}$

2

$2 \mathrm{R}_{1}=\mathrm{O}_{\mathrm{O}^{-}}^{\mathrm{O}} ; \mathrm{R}_{2}=\mathrm{H}$

5a $\mathrm{R}_{1}=\mathrm{H} ; \mathrm{R}_{2}=\xi^{5}=\mathrm{N}_{\mathrm{H}}$

$3 \mathrm{R}_{1}=\sum_{\mathrm{H}^{-}} \mathrm{N}^{\mathrm{O}} \mathrm{Ph} ; \mathrm{R}_{2}=\mathrm{H}$

5b $\mathrm{R}_{1}=\mathrm{H} ; \mathrm{R}_{2}=\xi^{5}=\mathrm{N}_{\mathrm{H}^{-}} \mathrm{Ph}$

$4 \mathrm{R}_{1}=\mathrm{H} ; \mathrm{R}_{2}={ }_{5}^{5}=\mathrm{O}$

5c $\mathrm{R}_{1}=\mathrm{H} ; \mathrm{R}_{2}=\mathrm{s}^{\mathrm{s}}=\mathrm{N}_{-} \mathrm{N}_{\text {। }}^{\prime}$<smiles>O=C(N/N=C/c1cc(C(F)(F)F)cc(C(F)(F)F)c1)c1ccccc1</smiles>

$\left.6 \mathrm{R}_{1}=\mathrm{H} ; \mathrm{R}_{2}={ }_{\mathrm{S}}^{\mathrm{s}} \mathrm{Y}^{\mathrm{O}}\right\rangle$ 


\section{Synthesis of compounds 1-7}

Compounds 1-7 were prepared by standard procedures for the synthesis of hydrazones and thioureas (Scheme 2). First, 3,5-bis(trifluoromethyl)phenyl isothiocyanate 10 was reacted in dichloromethane with anilines 8,9 and 13, to afford thioureas 1,2 and 6 , respectively. We tried to obtain the acylhydrazone-thiourea $\mathbf{3}$ from the analogous ester-thiourea $\mathbf{2}$, but all the conditions we used for the hydrazinolysis of the ester led to the degradation of the thiourea group. Thus, following an alternative synthetic route, ester $\boldsymbol{9}$ was treated in methanol with hydrazine as a cosolvent to obtain hydrazide $\mathbf{1 1}$. Subsequently, $\mathbf{1 1}$ was reacted with one equivalent of benzaldehyde in ethanol, and finally the resulting acylhydrazone $\mathbf{1 2}$ was reacted with isothiocyanate $\mathbf{1 0}$ to afford compound 3.

Acidic deprotection of the acetal group from thiourea 6 afforded the corresponding aldehyde 4 . This aldehyde was then treated separately with benzoylhydrazine 14a, phenylhydrazine $\mathbf{1 4 b}$ and $\mathrm{N}, \mathrm{N}$-dimethylhydrazine $\mathbf{1 4 c}$, in ethanol, to yield hydrazones $5 \mathrm{a}, \mathbf{5 b}$ and $\mathbf{5 c}$, respectively. In a similar way, acylhydrazone 7 was obtained by combining benzoylhydrazine 14a with 3,5bis(trifluoromethyl)benzaldehyde 15 in EtOH.

We also tried similar synthetic strategies to prepare aromatic (thio)ureas functionalized with an acylhydrazone group in the ortho position, but all attempts ultimately failed due to either undesired cyclizations yielding quinazolinediones, when going via ortho-ureido esters, ${ }^{27}$ or undesired reactions between the formed (thio)urea and the hydrazone, when going via ortho-amino hydrazones.

Scheme 2 Synthesis of the monothioureas 1-6 and acylhydrazone 7.

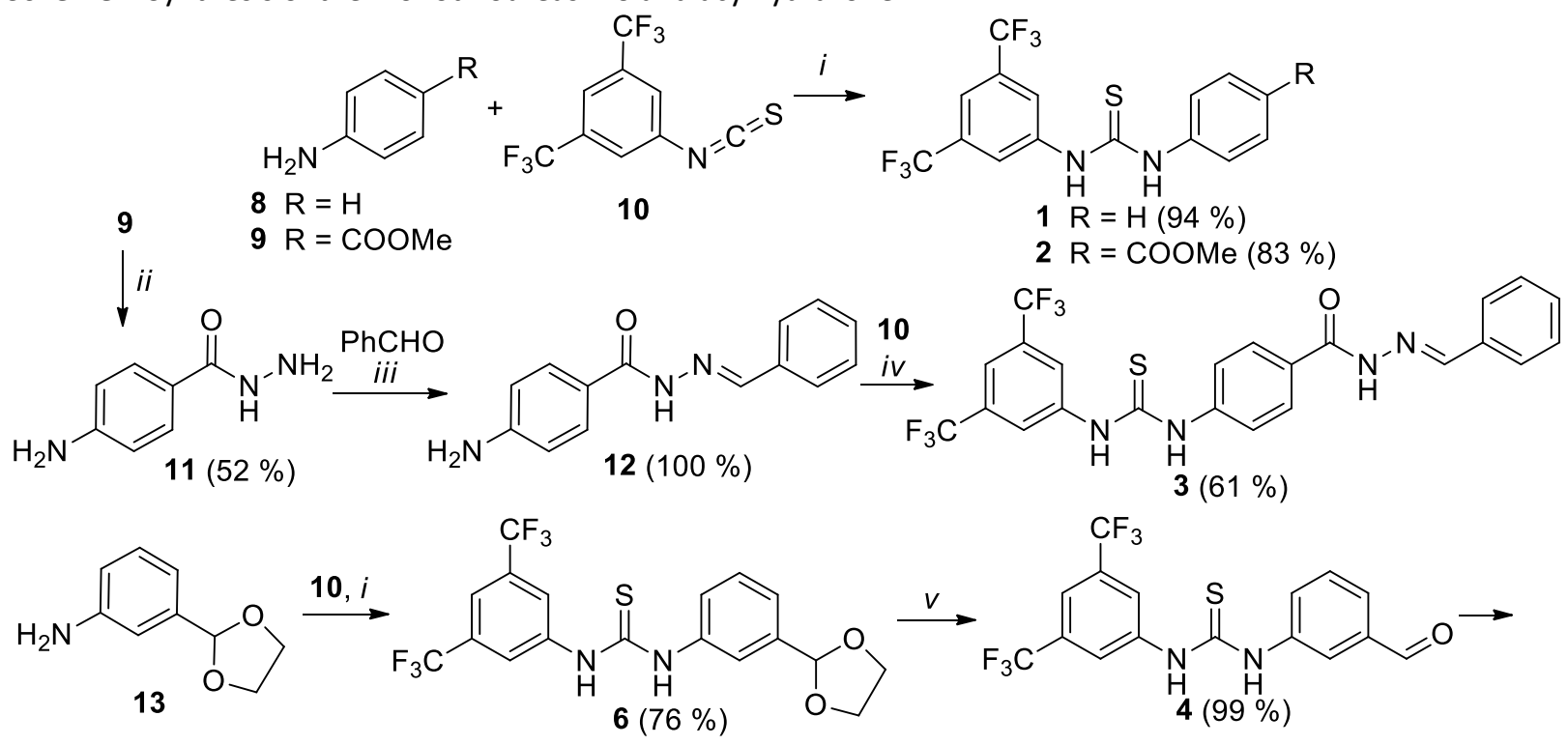
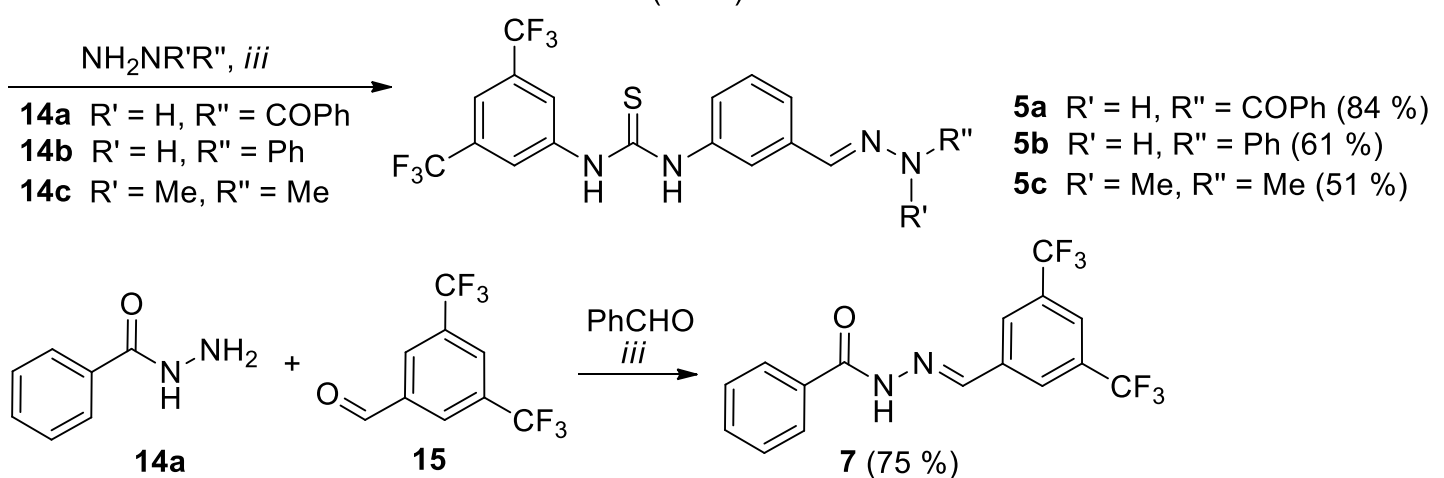

i: DCM, r.t., overnight; ii: $\mathrm{MeOH}: \mathrm{N}_{2} \mathrm{H}_{4} \cdot \mathrm{H}_{2} \mathrm{O}$ 2:1, reflux, 5h.; iii: EtOH, r.t., 1 - 16 h.; iv: DMF, rt, 20 min.; $v$ : TFA:DCM 9:1, r.t., 1 h. 


\section{Binding studies with mono-thioureas 1-6 and acylhydrazone 7}

The chloride binding properties of compounds 1-7 were studied by ${ }^{1} \mathrm{H}-\mathrm{NMR}$ titrations with tetrabutylammonium chloride (TBACl) in DMSO with $0.5 \%$ of $\mathrm{H}_{2} \mathrm{O}$, and the binding constants were determined by fitting the experimental data to $1: 1$ and 1:2 Host $(\mathrm{H})$ :Guest $(\mathrm{G})$ models with Bindfit v0.5 (Table 1). ${ }^{28}$ For monothioureas 1-6, the different fittings afforded similar binding constants for the first binding event in all cases $\left(\mathrm{K}_{11}=27-44 \mathrm{M}^{-1}\right)$. Thus, one should not expect significant differences in transport activity due to their affinity for the anion. On the other hand, the binding constant obtained for the reference acylhydrazone 7 was around one order of magnitude lower (4 $\left.\mathrm{M}^{-1}\right)$.

Table 1. logP values, chloride binding constants, electrostatic potential values, and relative chloride transport activity of compounds 1-7.

\begin{tabular}{|c|c|c|c|c|c|c|c|c|c|}
\hline \multirow{3}{*}{$\begin{array}{l}\text { Com- } \\
\text { pound }\end{array}$} & \multirow{3}{*}{$\log P^{a}$} & \multicolumn{3}{|c|}{$\mathrm{K}_{\mathrm{a}}\left(\mathrm{Cl}^{-}\right)\left(\mathrm{M}^{-1}\right)^{\mathrm{b}}$} & \multicolumn{4}{|c|}{$\begin{array}{l}\text { Electrostatic potential values }\left(V_{s, \max }\right) \\
\left(\mathrm{kcal} \mathrm{mol}^{-1}\right)^{\mathrm{d}}\end{array}$} & \multirow{3}{*}{$\begin{array}{l}\text { Relative } \\
\mathrm{Cl}^{-} \\
\text {transport }^{-} \\
\text {activity }^{\dagger}\end{array}$} \\
\hline & & \multirow{2}{*}{$\begin{array}{l}1: 1 \text { model } \\
K_{11}\left(M^{-1}\right)\end{array}$} & \multicolumn{2}{|c|}{$1: 2$ model } & \multirow{2}{*}{$\begin{array}{c}\text { thiourea } \\
\mathrm{N}-\mathrm{H}^{\mathrm{e}}\end{array}$} & \multicolumn{3}{|c|}{ hydrazone } & \\
\hline & & & $K_{11}\left(M^{-1}\right)$ & $K_{12}\left(M^{-1}\right)$ & & $\mathrm{N}-\mathrm{H}$ & $\mathrm{C}_{\text {hyd }}-\mathrm{H}$ & $\mathrm{C}_{\mathrm{ar}}-\mathrm{H}$ & \\
\hline 1 & 5.5 & 33 & - & - & 91.7 & - & - & - & Good \\
\hline 2 & 5.3 & 42 & - & - & 97.0 & - & - & - & Good \\
\hline 3 & 6.8 & $42^{c}$ & 44 & 7 & 96.7 & 61.1 & 53.6 & 54.9 & Poor \\
\hline 4 & 5.2 & 37 & - & - & 99.3 & - & - & - & Good \\
\hline $5 a$ & 6.8 & $28^{\mathrm{c}}$ & 30 & 4 & 95.4 & 60.0 & 52.8 & 54.1 & Poor \\
\hline $5 b$ & 6.9 & $27^{c}$ & 24 & 5 & 92.9 & 51.0 & 42.7 & 41.7 & Poor \\
\hline $5 c$ & 5.5 & 32 & - & - & 89.7 & - & - & - & Moderate \\
\hline 6 & 5.3 & 32 & - & - & 90.0 & - & - & - & Moderate \\
\hline 7 & 5.2 & 4 & - & - & - & 71.5 & 65.2 & 64.5 & Poor \\
\hline
\end{tabular}

${ }^{a}$ Calculated values using ChemDraw 19.0.

${ }^{b}$ Determined by ${ }^{1} \mathrm{H}$ NMR titration in DMSO-d6: $\mathrm{H}_{2} \mathrm{O}$ 99.5:0.5.

c Determined by fitting only the signals of the thiourea group to a 1:1 model.

${ }^{d}$ Computed on the electron density surface of the thiourea and hydrazone binding units at the bond critical points in the $\mathrm{N}-\mathrm{H} \cdots \mathrm{Cl}^{-}$or $\mathrm{C}-\mathrm{H} \cdots \mathrm{Cl}^{-}$interactions between the thiourea or hydrazone binding units and chloride.

e The $V_{s}$ values for the two thiourea $\mathrm{N}-\mathrm{H}$ binding units are undistinguishable.

${ }^{f}$ Established from the comparison of the transport curves at 1:100 transporter-lipid molar ratio.

Despite the similar $\mathrm{Cl}^{-}$binding affinities obtained for compounds 1-6 when fitted to a 1:1 model, the titrations indicated some differences in the anion binding properties of the compounds. As an example, Figure 1a shows the spectra from the titration of thiourea $\mathbf{5 a}$, which contains an acylhydrazone substituent in the meta position of one of the aryl rings. The signals labelled as a-e are those most affected by the addition of TBACl. The variation of the chemical shifts show a different pattern for the signals corresponding to the thiourea moiety $(a-c)$ and for the signals corresponding to the acylhydrazone ( $d$ and $e$ ). While signals $a$ - $c$ show a saturation profile, signals $d$ and e show an almost linear dependence of the concentration of TBACl (Figure 1b). Interestingly, signals $a-c$ fitted well to a 1:1 model $\left(K_{11}=28 \mathrm{M}^{-1}\right)$, but when signals $\mathrm{d}$ and e were added to the fitting a 1:2 model was required to obtain a good fitting between all observed and calculated chemical shifts $\left(\mathrm{K}_{11}=30 \mathrm{M}^{-1}, \mathrm{~K}_{12}=4 \mathrm{M}^{-1}\right)$ (Figure S9). This evidenced that molecule 5a contains two separate binding sites that bind the anions independently, the thiourea and the acylhydrazone groups, which agrees with the structural rigidity of the molecule. Moreover, the $\mathrm{K}_{11}$ values obtained from both models were very similar, suggesting that during the titration the first chloride binds predominantly to the thiourea, which is the group with a higher affinity for the anion, and the second chloride binds to the acylhydrazone group (note that $K_{12}$ is similar to the $K_{11}$ obtained for 7 , Table 1). 
a)
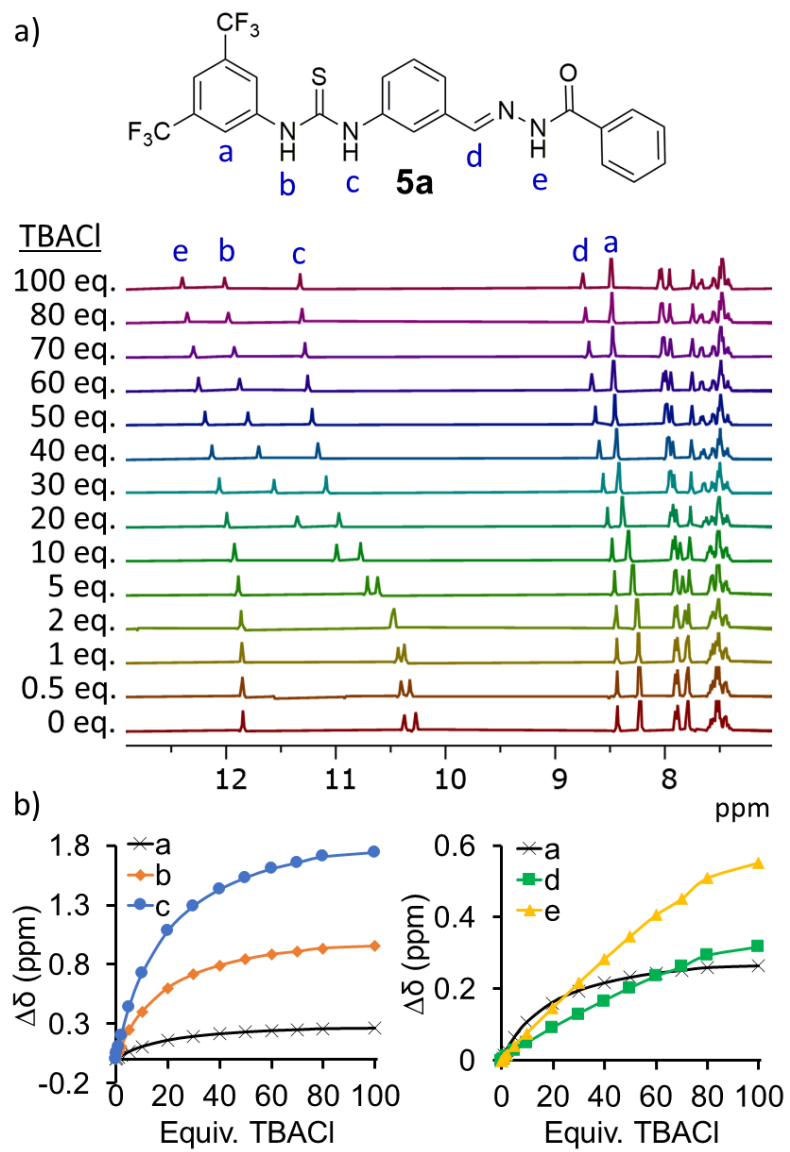

Figure 1. ${ }^{1} \mathrm{H}-\mathrm{NMR}$ titration of compound $\mathbf{5 a}(2 \mathrm{mM})$ in DMSO- $\mathrm{d}_{6}: \mathrm{H}_{2} \mathrm{O}$ (99.5:0.5) with different amounts of tetrabutylammonium chloride (TBACl).

Similar results were obtained for hydrazone-derivatives $\mathbf{3}$ and $\mathbf{5 b}$. For these titrations, Table 1 shows the binding constants obtained from the fitting of three signals to a 1:1 model (e.g., signals a-c for compound 5a) and also the binding constants obtained for the fitting of five signals to a 1:2 model (e.g., signals a-e for compound 5a) (Figures S6 and S11).

In contrast to the observations described for compound $\mathbf{5 a}$, the signals of the precursor aldehyde 4 affected by the addition of TBACl were well fitted with a 1:1 model (Figures S7 and S8). The signal around $10 \mathrm{ppm}$, corresponding to the $\mathrm{C}-\mathrm{H}$ of the aldehyde, did not show noticeable changes in chemical shift during the titration. This contrasts with the significant effect observed on signal $d$ of compound $\mathbf{5 a}$ (Figure 1 ) and confirms that only one chloride anion is bound by thiourea 4. Similar results were obtained for compounds $1,2,5$ and 6 (see section 3.2 of Supplementary information).

\section{DFT calculations on chloride complexes of 1-7}

Further insights into the anion binding affinity of receptors 1-7 were obtained by density functional theory (DFT) geometry optimizations of their chloride complexes, using Gaussian $16 .{ }^{29}$ These calculations were carried out at the PBE-0/Def2TZVP theory level, employing Grimme's D3 empirical correction for dispersion ${ }^{30}$ and the conductor-like polarizable continuum model (CPCM) to account for DMSO solvation effects. ${ }^{31,32}$ Receptors $\mathbf{1 , 2}$, 4, 5c and $\mathbf{6}$ were optimised with chloride bonded to the thiourea binding unit, while $\mathbf{3}, \mathbf{5 a}$, and $\mathbf{5} \mathbf{b}$ derivatives, in agreement with the 1:2 receptor:anion stoichiometry suggested by ${ }^{1} \mathrm{H}$ NMR titration data for these three receptors (see Tables 1), were optimised with a chloride positioned nearby each binding unit. The electronic structure of the chloride complex of $\mathbf{7}$ was also ascertained by DFT calculations, with the chloride putatively hydrogen bonded to the acylhydrazone. The computed structures of $\mathbf{3}$ and $\mathbf{5 a}$ chloride complexes are shown in Figure $2 \mathrm{a}$, while the structures of the remaining complexes are presented in Figures SC1 and SC2. 
a)

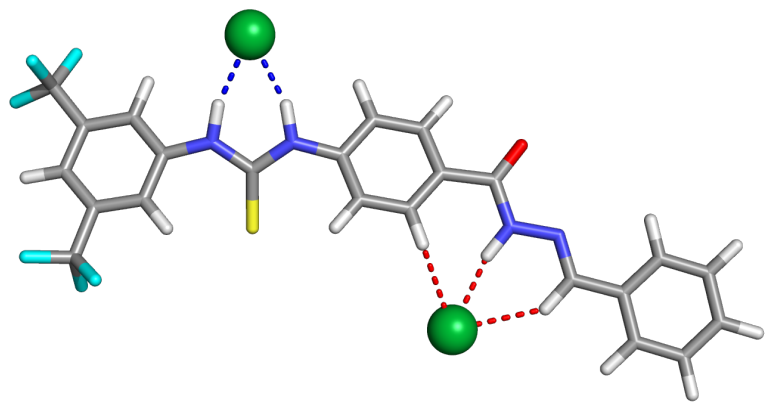

3

b)

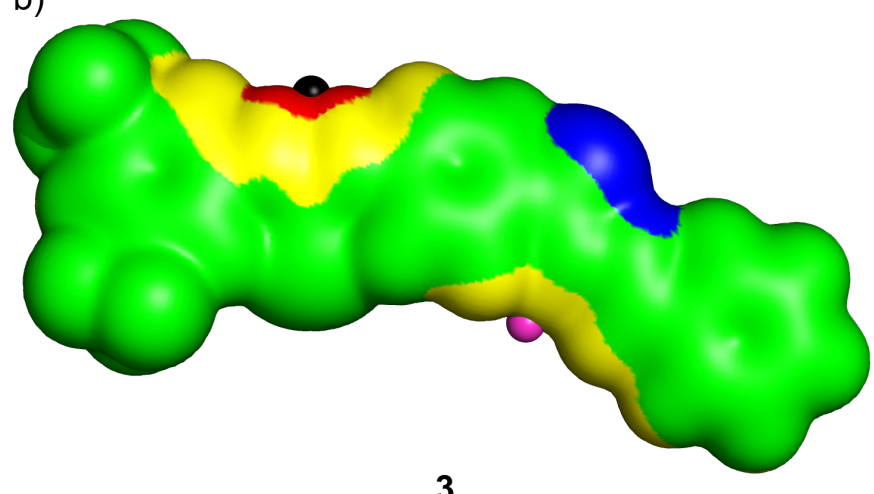

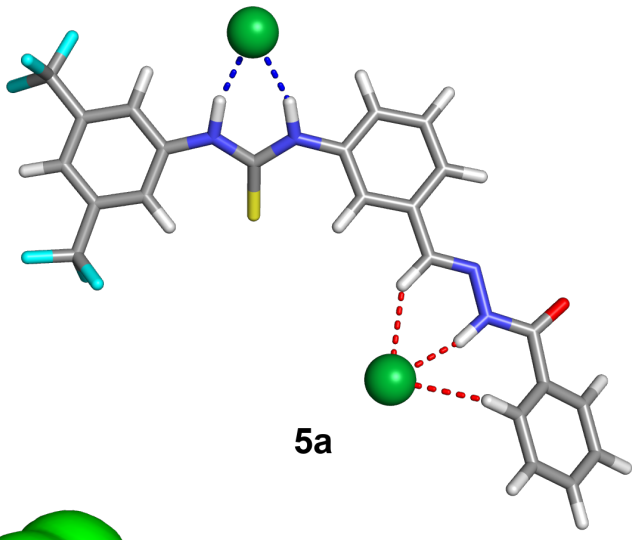

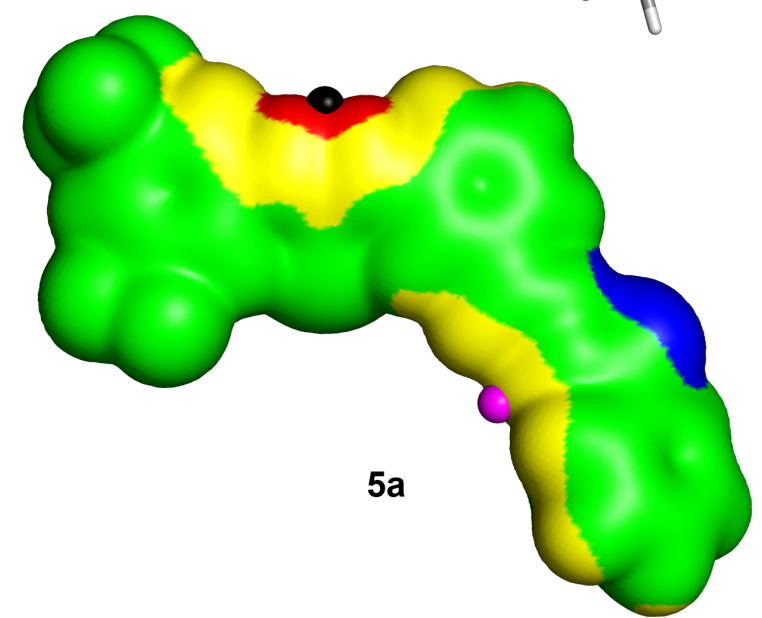

Figure 2. a) DFT optimized structures of the $1: 2$ chloride complexes of $\mathbf{3}$ and $\mathbf{5 a}$. The $\mathrm{N}-\mathrm{H} \cdots \mathrm{Cl}$ - hydrogen bonds at the thiourea binding sites are drawn in blue, while the $\mathrm{N}-\mathrm{H}^{\cdots} \cdot \mathrm{Cl}^{-}$and $\mathrm{C}-\mathrm{H} \cdots \mathrm{Cl}^{-}$interactions with the acylhydrazone binding units are drawn in red; b) Distributions of the electrostatic potential of $\mathbf{3}$ and $\mathbf{5 a}$ mapped on their molecular surfaces (0.001 e Bohr ${ }^{-1}$ contour). The surface colour ranges from -30 (blue) to $70 \mathrm{kcal} \mathrm{mol}^{-1}$ (red). The location of the $V_{\mathrm{s}, \max }$ in front of the thioureas is shown with a black sphere, while the location of the highest value of $V_{s}$ in front of the acylhydrazone is show with a pink one.

The computed dimensions of the $\mathrm{N}-\mathrm{H} \cdots \mathrm{Cl}^{-}$and $\mathrm{C}-\mathrm{H} \cdots \mathrm{Cl}^{-}$hydrogen bonds in the chloride associations are gathered in Table SC1. Overall, the thiourea $\mathrm{N} \cdots \mathrm{Cl}^{-}$distances and $\mathrm{N}-\mathrm{H}^{\prime} \cdots \mathrm{Cl}^{-}$angles, ranging between 3.15 and $3.20 \AA$ and 161.6 and $165.3^{\circ}$, are comparable in the complexes of 1-6. However, in agreement with the variations of the resonances of protons $b$ and $c$ observed in the ${ }^{1} \mathrm{H}$ NMR titrations (as illustrated in Figure $1 \mathrm{a}$ ), the distances found between the $\mathrm{N}-\mathrm{H}_{\mathrm{b}}$ thiourea binding unit directly attached to the fluorinated ring and chloride are slightly shorter (ca. $0.04 \AA$ ) than the second thiourea binding unit $\left(\mathrm{N}-\mathrm{H}_{\mathrm{c}}\right)$, suggesting that these two convergent hydrogen bonds have different binding strengths, as further demonstrated through the Quantum Theory of Atoms in Molecules (QTAIM) and Natural Bond Orbital (NBO) methods. The results of these two complementary analyses are detailed in the ESI on computational studies.

In the complexes of isomeric compounds $\mathbf{3}$ and $\mathbf{5 a}$ and of $\mathbf{7}$, the chloride binding by the acylhydrazone binding motif occurs mainly through a $\mathrm{N}-\mathrm{H} \cdots \mathrm{Cl}^{-}$hydrogen bond (proton $e$ in Figure 1a), assisted by two convergent $\mathrm{C}-\mathrm{H} \cdots \mathrm{Cl}^{-}$bonding contacts established with the hydrazone proton ( $\mathrm{C}_{\text {hyd }}-\mathrm{H}$, proton $d$ in Figure $1 \mathrm{a}$ ) and an aromatic proton $\left(\mathrm{C}_{\mathrm{ar}}-\mathrm{H}\right)$ adjacent to the acyl group (see Figure 2a). The $\mathrm{N}-\mathrm{H} \cdots \mathrm{Cl}^{-}$hydrogen bonds are stronger than the $\mathrm{C}_{\text {hyd }}-\mathrm{H} \cdots \mathrm{Cl}^{-}$ones, displaying shorter distances and more linear angles ( $3.26 \pm 0.01$ vs $3.57 \pm 0.01 \AA$ and $166.5 \pm 0.4$ vs $144.3 \pm 0.5^{\circ}$, see Table SC 1 ), in line with the variations on the chemical shifts of protons $e$ and $d$, illustrated in Figure 1a for 5 a. Furthermore, the dimensions of the $\mathrm{C}_{\mathrm{ar}}-\mathrm{H} \cdots \mathrm{Cl}^{-}$hydrogen bonds $\left(3.59 \pm 0.01 \AA\right.$ and $\left.142.9 \pm 3.0^{\circ}\right)$ hint at their comparable strength to the $\mathrm{C}_{\text {hyd }}-\mathrm{H} \cdots \mathrm{Cl}^{-}$ones. While the $\mathrm{NH}$ phenylhydrazone binding unit of $\mathbf{5 b}$ binds chloride with equivalent strength to the acylhydrazone analogous, the $\mathrm{C}-\mathrm{H}$ groups pointing to the anion at larger distances (ca. $0.3 \AA$ ) than in $\mathbf{3}$ and $\mathbf{5 a}$, reflect the absence of acyl electronwithdrawing effect. 
Having established the structures of the receptors in the chloride complexes, the binding ability of 1-7 was ascertained through the distribution of the electrostatic potential plotted onto their electron density surface $\left(V_{S}\right)$. The distributions of $V_{S}$ are depicted for the acylhydrazone isomers $\mathbf{3}$ and $\mathbf{5 a}$ in Figure $2 \mathrm{~b}$ and in Figure SC3 for the remaining receptors, while the most relevant values of $V_{S}$ are gathered in Table 1. Overall, the thiourea motifs of derivatives 1-6 are enclosed in red areas of highly positive potential and the highest value of $V_{S}\left(V_{s, \max }\right)$ is located in front of its $\mathrm{NH}$ binding sites, as depicted in Figure $2 b$ by black dots. The $V_{s, \max }$ values range between 89.7 and 99.3 $\mathrm{kcal} \mathrm{mol}^{-1}$ for the thiourea binding units (see Table 1), while the values obtained for the hydrazone moieties are below $72 \mathrm{kcal} \mathrm{mol}^{-1}$. This analysis suggests a superior binding affinity of the thiourea for chloride, although the $V_{\mathrm{S}}$ values estimated for the hydrazone binding motifs corroborate the existence of 1:2 chloride species, as indicated by the fitting models of the ${ }^{1} \mathrm{H}$ NMR data. Further assessment of the association strength between chloride and 1-7, were obtained from their interaction energies, as well from the QTAIM and NBO analyses of their hydrogen bonds, as discussed in the computational ESI, and showed that the thiourea and hydrazone binding motifs in $\mathbf{3}, \mathbf{5 a}$, and $\mathbf{5 b}$ recognise chloride in a non-cooperative manner.

\section{Transport studies with monothioureas}

To determine the chloride transport properties of our compounds we used the wellestablished lucigenin assay. For this, large unilamelar vesicles (LUVs) of POPC and cholesterol (7:3 ratio) with an average diameter of $\sim 150 \mathrm{~nm}$ (verified by DLS, see Section 5.1 of Supplementary Information) were prepared with the intra- and extravesicular media buffered with $225 \mathrm{mM} \mathrm{NaNO}_{3}$ and $1 \mathrm{mM}$ HEPES at $\mathrm{pH} 7.4$, and with the chloride sensitive dye lucigenin encapsulated inside the vesicles $(0.8 \mathrm{mM})$. Initially, the transporter was added to a sample of vesicles as an external stock solution in an organic solvent $\left(\mathrm{CH}_{3} \mathrm{CN}\right.$ or $\left.\mathrm{MeOH}\right)$ and the mixture was equilibrated by stirring it at $25^{\circ} \mathrm{C}$ inside a fluorometer. The transport was initiated by an extravesicular pulse of $\mathrm{NaCl}(25 \mathrm{mM})$ and the kinetics of chloride influx was monitored via the quenching of the fluorescence of lucigenin (caused by chloride inside the vesicles) over time. It is assumed that the transport of chloride into the vesicles will be compensated by transport of $\mathrm{NO}_{3}{ }^{-}$out of the vesicles, to maintain the charge balance at both sides of the membrane $\left(\mathrm{Cl}^{-} / \mathrm{NO}_{3}{ }^{-}\right.$antiport).

All compounds were studied at a 1:100 transporter to lipid molar ratio ( $1 \mathrm{~mol} \%$ ). At this concentration thiourea 1, without substituents on the phenyl ring, showed good transport activity and acylhydrazone 7, with a lower $\mathrm{Cl}^{-}$affinity, was almost inactive (Figure 3a). Thioureas $\mathbf{2}$ and $\mathbf{3}$ contain an ester and an acylhydrazone groups in para position, respectively. Although these two functional groups have similar electronic effects on the aromatic ring (as confirmed by the nearly identical $\mathrm{K}_{\mathrm{a}}$ values for $\mathrm{Cl}^{-}$and $V_{s}$ values of their thiourea $\mathrm{NHs}$ ), compounds $\mathbf{2}$ and $\mathbf{3}$ showed remarkably different transport activities. While the activity of compound $\mathbf{2}$ was almost identical to that by reference compound $\mathbf{1}$, the transport activity of $\mathbf{3}$ was surprisingly low (nearly inactive).

Next, we performed analogous transport experiments with thioureas 4-6, which contained different substituents in the meta position of the aryl ring (Figure 3b). Like compound 3, thiourea 5a also has an acylhydrazone group, but in this case that group is in a different position and bound from the azomethine carbon. Despite this different substitution pattern, compound $\mathbf{5 a}$ also showed an almost negligible transport activity, and this contrasted with the much better transport of the precursor aldehyde 4, which showed very similar activity to that of the reference thiourea 1. Compounds $\mathbf{3}$ and $\mathbf{5 a}$, with logP values close to 7, are more lipophilic than the more active thioureas 1, 2 and 5, whose logP values are around 5.5 (Table 1). This higher lipophilicity can result in a poor partition of compounds $\mathbf{3}$ and $\mathbf{5 a}$ into the membranes of the vesicles when they are added as external solutions, and this could be a reason for their low transport activity. ${ }^{7}$ In order to discard an inadequate delivery of these compounds to the membranes of the vesicles, we confirmed their poor transport activity by preincorporating them during the preparation of the vesicles (Figure S32). ${ }^{33,34}$ 
Moreover, stability studies were performed to rule out the degradation of compounds $\mathbf{3}$ and $\mathbf{5 a}$ as a reason for their low activity (see Section 4 of Supplementary Information).
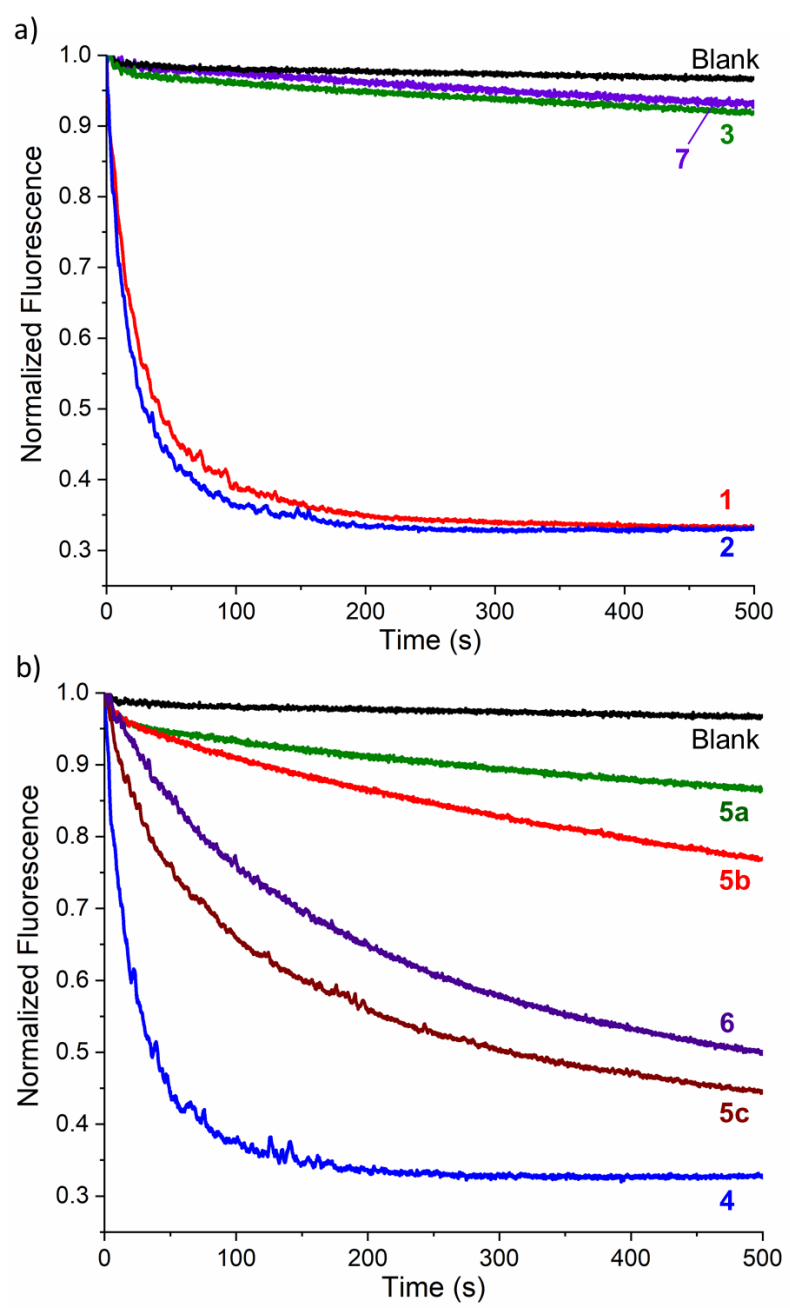

Figure 3. Transport of $\mathrm{Cl}^{-}$by compounds 1-7 (at 1:100 transporter to lipid molar ratio) as monitored by the lucigenin assay in $225 \mathrm{mM} \mathrm{NaNO}_{3}$ with $1 \mathrm{mM} \mathrm{HEPES}$ at $\mathrm{pH} 7.5$, upon addition of $25 \mathrm{mM} \mathrm{NaCl}$. The transporters were added to the solution of vesicles ( $3 \mathrm{~mL}, 0.4 \mathrm{mM}$ lipids) as $\mathrm{CH}_{3} \mathrm{CN}$ or $\mathrm{CH}_{3} \mathrm{OH}$ solutions $(6 \mu \mathrm{L}$ ) 5 minutes before the addition of $\mathrm{NaCl}$ (pure $\mathrm{CH}_{3} \mathrm{CN}$ was added for the blank curve). a) Reference thiourea 1, reference acylhydrazone 7 and para-substituted thioureas 2 and 3. b) Meta-substituted thioureas $4,5 a, 5 b, 5 c$ and 6 .

As $\mathbf{5 a}$, compounds $\mathbf{5 b}$ and $\mathbf{5 c}$ are hydrazones obtained from aldehyde $\mathbf{4}$. From the two new hydrazones, phenyl hydrazone $\mathbf{5 b}$ is the most similar in structure and binding properties to acylhydrazone $\mathbf{5 a}$, and its transport activity was only slightly better than that of $\mathbf{5 a}$. The main differences between these two compounds are that $\mathbf{5 b}$ lacks the acyl group adjacent to the hydrazone in $\mathbf{5 a}$ and that the hydrazone- $\mathbf{N H}$ of $\mathbf{5 b}$ is a bit less acidic than that of $\mathbf{5 a}$. This suggested that the acidic hydrazone-NH groups might be responsible for the poor transport by those thioureas. Unlike hydrazones $\mathbf{5 a}$ and $\mathbf{5 b}$, hydrazone $\mathbf{5} \mathbf{c}$ has no acidic $\mathbf{N H}$. This compound performed much better than the former two, supporting our hypothesis about the detrimental effect of acidic NHs in the transport activity of hydrazone functionalized thioureas. Our binding studies suggested that the hydrazone groups in compounds $\mathbf{3}, \mathbf{5} \mathbf{a}$ and $\mathbf{5 b}$ can bind a second anion, different to that bound to the thiourea, and this is something to take into account not only when considering the interaction of the transporters with chloride but also with the phospholipid head groups of the membrane. Fluorescence studies performed with labelled tripodal sulphonamides have indicated that those compounds mainly reside in the water-membrane interphase of phosphatidylcholine vesicles. ${ }^{35}$ In agreement with this, various molecular dynamic studies have suggested that urea, thiourea and squaramide-based transporters locate mainly in the water-membrane interphase and interact with 
the phosphate of the phospholipids, when they are embedded in membranes. ${ }^{36-38}$ Moreover, more recent voltage-dependent transport studies performed in LUVs have demonstrated that some transporters cannot diffuse through the membrane of vesicles as neutral molecules due to their strong binding to the phospholipid head groups, but they can bind chloride and diffuse as transporter-anion complexes. ${ }^{10}$ It should be noted that it is geometrically impossible for the thiourea and the hydrazone groups in compounds $\mathbf{3}, \mathbf{5 a}$ and $\mathbf{5 b}$ to bind the same anion. Thus, the presence of two independent binding sites in these molecules might be the reason for their poor transport properties. A thiourea with a single binding site probably interacts (in some extent) with the phospholipid head groups and anions in the water-membrane interphase compete for this binding site, to then get transported through the membrane (Figure 4a). On the other hand, in a molecule with two separate binding sites (such as $\mathbf{5 a}$ ), the anion can bind to one of those binding sites, but the other can still interact with the phospholipid head groups, which could hinder the diffusion of the transporter-anion complex through the membrane (Figure $4 \mathrm{~b}$ ).

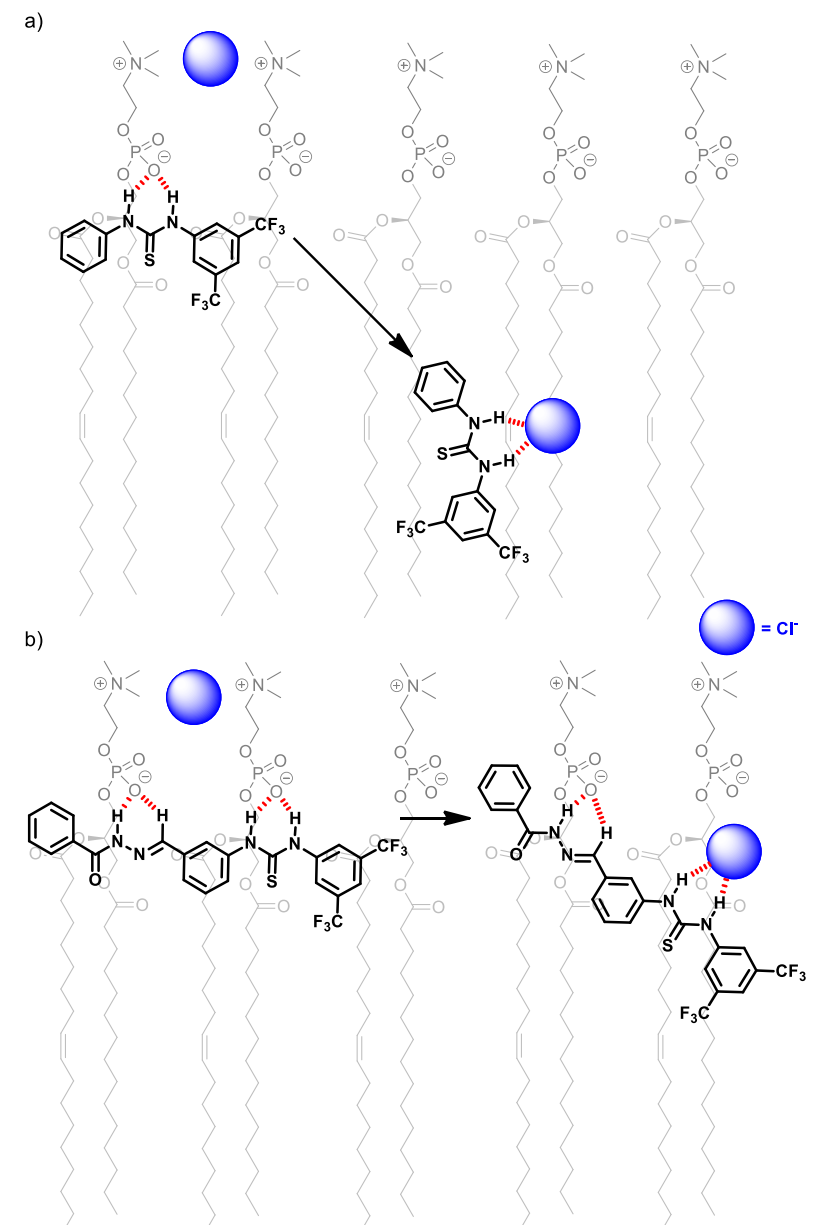

Figure 4. Representation of the formation of an anion-transporter complex for compounds $\mathbf{1}$ (a) and $\mathbf{5 a}$ (b), as the first step in their performance as mobile carriers. We propose that the acylhydrazone group in 5a can hinder the diffusion of the complex by interacting with the phospholipid head groups.

As an alternative to our hypothesis stated above to explain the poor transport by the acylhydrazone-thioureas, one could also propose the deprotonation of the acidic hydrazone-NHs as the main reason for the poor transport activity of compounds $\mathbf{3}, \mathbf{5 a}$ and $\mathbf{5 b}$. To rule out this possibility, we performed transport experiments with hydrazone derivatives $\mathbf{5} \mathbf{a}$ and $\mathbf{5} \mathbf{b}$, and the precursor aldehyde 4 as a reference, at pH 5.0 (Figure S33). ${ }^{39}$ The transport curves obtained at that low $\mathrm{pH}$ for the three compounds studied were very similar to those obtained at $\mathrm{pH} 7.5$, which indicated that deprotonation is unlikely to be the reason for the poor performance of hydrazonefunctionalized thioureas. 
Our studies also suggested a more subtle effect of the $\mathrm{N}, \mathrm{N}$-dimethylhydrazone group in compound $\mathbf{5 c}$, which has no $\mathrm{H}$-bond donor groups but two nitrogen that can act as $\mathrm{H}$-bond acceptors. Although this compound showed significant transport activity, it was noticeably less active than the reference thiourea 1 (Figure 3). In addition, compound 6 (the acetal-protected version of aldehyde 4 ) showed moderate activity, like that of $\mathbf{5 c}$ (Figure $3 \mathrm{~b}$ ). Electronic effects cannot explain the decreased activity of $\mathbf{5 c}$ and $\mathbf{6}$ compared to $\mathbf{1}$, as demonstrated by the identical binding constants of these three compounds. Similarly to what we have proposed before for hydrogen bond donor groups, hydrogen bond acceptor groups could affect the transport activity of the compounds by interacting with the polar groups of the membrane. This negative effect for the hydrogen bond acceptor groups in compounds $\mathbf{5} \mathbf{c}$ and $\mathbf{6}$ is much lower than that of hydrogen bond donor groups in compounds $\mathbf{3}, \mathbf{5 a}$ and $\mathbf{5 b}$, and could probably be overcome by additional structural modifications.

If the hydrazone substituents are affecting the anion transport properties of the thioureas by hindering the mobility of the anion-transporter complexes in the membrane, they might also affect other transport processes, such as protonophore activity. Some (thio)ureas can act as protonophores by protonation-deprotonation of their acidic $\mathrm{NH}$ groups at both sides of the membrane. This implies, in principle, the diffusion of the deprotonated compound through the membrane in one way and the diffusion of the neutral molecule in the opposite sense. Thus, considering this possibility, we also studied the protonophore activity of compounds $\mathbf{1}, \mathbf{5 a}, \mathbf{5 b}$ and 5c, and we found that indeed they showed a similar trend to that described above for $\mathrm{Cl}^{-} / \mathrm{NO}_{3}{ }^{-}$ antiport ( $\mathbf{1} \approx \mathbf{5} \mathbf{c}>\mathbf{5 b}>\mathbf{5 a}$; Figure S36). Probably the hydrazone groups in compounds $\mathbf{5 a}$ and $\mathbf{5 b}$ also hinder the diffusion of the deprotonated adducts through the membrane due to additional interactions with the phospholipids head groups. Nevertheless, it should also be noted that all compounds showed protonophore activities, which indicates that the free compounds are present in the membranes and that their mobility through the bilayer is not completely prevented.

Additional studies with other acylhydrazone-based receptors confirmed that acylhydrazones are poor chloride transporters (see Section 7 of Supplementary Information). Our results strongly suggest that the best strategy to obtain hydrazone-based anion transporters is to avoid the presence of acidic hydrazone NHs and use other functional groups as the binding motifs, as in the case of compound 5c. Thus, this study encourages the use of hydrazones without NHs, as well as ester and acetal groups, in the development of structurally complex anion transporters from DCL.

\section{Anion transporters with separate binding sites}

The results discussed in the previous section suggested that a molecule with two separate binding sites (which cannot bind the same anion) might perform poorer as chloride transporter compared to a molecule with only one binding site. To study if this hypothesis is a general trend in urea and thiourea based anion transporters we compared the transport activity of ureas 16, 17 and 18 (Scheme 3). Ortho-phenylenebisureas contain two urea groups well preorganized to bind the same anion and have been previously described as very efficient transporters. ${ }^{33,36}$ Indeed the concentration of the ortho-phenylene bisurea 17 required to show similar activity to that of the monourea 16 was 100 times lower, indicating a much higher activity (Figure 5). On the other hand, the meta-phenylene bisurea $\mathbf{1 8}$ is a structural isomer of $\mathbf{1 7}$ whose rigidity and substitution pattern prevents the binding of the same anion by the two urea groups, as was the case with the thiourea and hydrazone groups in compounds $\mathbf{5 a}$ and $\mathbf{5 b}$. In agreement with our expectations, bis-urea $\mathbf{1 7}$ showed a transport activity much lower than that of the monourea 16. 
Scheme 3. Structures of the (bis)ureas 16-18 and bisthiourea 19.<smiles>O=C(Nc1ccccc1)Nc1ccccc1NC(=O)Nc1cc(C(F)(F)F)cc(C(F)(F)F)c1</smiles><smiles>[Y]C(Nc1cccc(NC([X])Nc2cc(C(F)(F)F)cc(C(F)(F)F)c2)c1)=[W][Ba]</smiles>

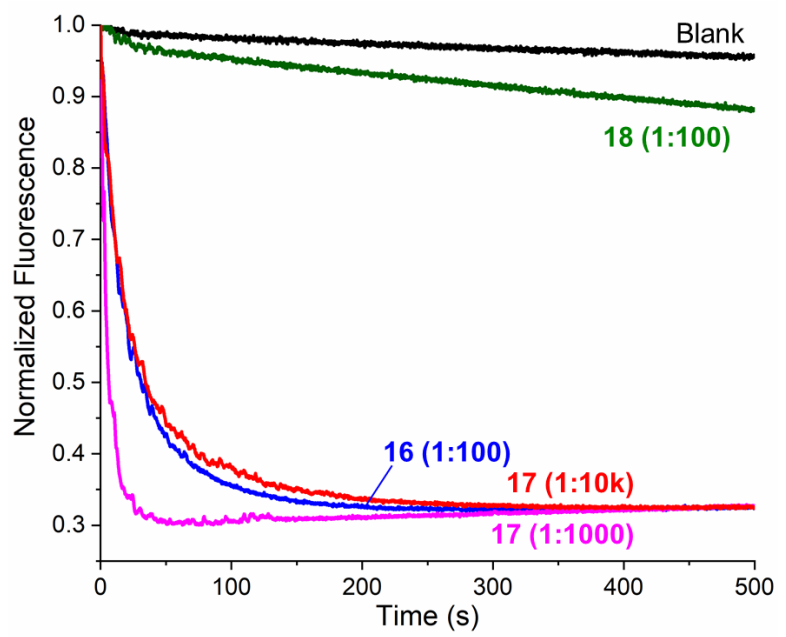

Figure 5. Transport of $\mathrm{Cl}^{-}$by compounds 16,17 and 18 as monitored by the lucigenin assay in $225 \mathrm{mM} \mathrm{NaNO}_{3}$ with 1 $\mathrm{mM}$ HEPES at $\mathrm{pH} 7.5$, upon addition of $25 \mathrm{mM} \mathrm{NaCl}$. The transporters were added to the solution of vesicles ( $3 \mathrm{~mL}, 0.4$ mM lipids) as $\mathrm{CH}_{3} \mathrm{OH}$ solutions $(6 \mu \mathrm{L}) 5$ minutes before the addition of $\mathrm{NaCl}$ (pure $\mathrm{CH}_{3} \mathrm{OH}$ was added for the blank curve). The concentration of transporter is indicated between parenthesis as the transporter to lipid molar ratio.

We also studied the meta-phenylene bisthiourea 19, and although it showed a chloride binding constant for the first binding event $\left(K_{11}=50 \mathrm{M}^{-1}\right.$, Figure S19) slightly higher than that of the monothioureas 1-6 its transport activity was identical to that of bisurea $\mathbf{1 8}$ (Figure S34). It should be noted that the effect of the two independent binding sites that we propose here can depend on the nature of the binding motifs. In contrast to the low transport activity of our meta-phenylene bis(thio)ureas 18 and 19, a meta-phenylene bisiminourea has been reported with a similar transport activity than that of analogous ortho-phenylene bisiminoureas. ${ }^{40}$ Since transport by iminourea groups relies on protonation, probably one of the two iminoureas is protonated for transport while the other one does not get protonated and therefore it does not hinder the diffusion of the complex through the membrane by interaction with the phospholipid head groups.

The high contrast between the transport activities of bisureas $\mathbf{1 7}$ and $\mathbf{1 8}$ evidenced that an inadequate distribution of multiple binding units in a rigid structure can yield receptors with multiple independent binding sites, and this can be detrimental for their anion transport activity. It is uncommon to find in the literature anion transporters with separate binding sites, because anion transporters are rationally designed to have all their binding units interacting with the same anion. A clear example of molecules with two separate binding sites studied as chloride transporters is a family of azobenzenes functionalized with two squaramides as the anion binding motifs. ${ }^{41}$ These molecules are photoswitchable anion receptors that present two conformers with very different 
spatial separation between the two binding units. While the $Z$ conformers distribute the two squaramides close enough for them to bind the same anion, the $E$ conformers have the squaramide units too far in space to bind the same anion. Therefore, the $Z$ conformers exhibited much better chloride binding and transport properties than the $E$ conformers. In addition, a monosquaramide used as a reference non-photoresponsive transporter showed a better transport activity than the analogous $E$-azobenzene. Like with our molecules, this observation cannot be explained based on the binding properties of the molecules, but it would agree with our hypothesis of the two independent binding sites. Moreover, also in agreement with our hypothesis, another study performed with similar azobenzene-based transporters functionalized with urea and thiourea groups also showed that the $E$ conformers were inactive in conditions in which mono(thio)ureas had showed clear transport activity. ${ }^{42-44}$

\section{Molecular Dynamics simulations in a POPC membrane model}

The anion transport ability of this series of molecules was further investigated at the atomistic level, with the interaction and diffusion of selected compounds in a POPC membrane model with Molecular Dynamics (MD) simulations. In agreement with the chloride efflux studies, 1 and $\mathbf{2}$ were selected as good transporters; $\mathbf{5 c}$ as a moderate transporter; and 3, 5a, $\mathbf{5 b}, \mathbf{7}$ and $\mathbf{1 9}$ were chosen as prototypes of poor transporters. The membrane system was composed of 128 POPC lipids, described with lipid17, ${ }^{45} 6500$ TIP3P water molecules, ${ }^{46} 18 \mathrm{Na}^{+}$and $18 \mathrm{Cl}^{-}$ions, described with suitable 12-6 Lennard Jones parameters, ${ }^{47}$ affording a ca. $0.15 \mathrm{M}$ concentration. The transporters were described with GAFF2 ${ }^{48}$ and RESP atomic charges, ${ }^{49}$ and their chloride complexes were randomly positioned at the centre of the POPC bilayer (scenario $\mathcal{P}$ ), or alternatively, in the water phase (scenario $\mathcal{W}$ ). AMBER $18^{50,51,52}$ was used to run independent MD simulations amounting to a simulation time of $1.35 \mu$ s for each small molecule, except for $\mathbf{3}$ and $\mathbf{5 a}$, which were simulated for $4.05 \mu$ s each. Additional details are given in ESI.

The diffusion of the synthetic transporters was monitored following the relative distances of selected referential points (centres of mass of the aromatic rings, named A, B and C, see Figure 6) towards the closest water/lipid interface, allowing to infer the position and orientation of the molecules along the bilayer normal ( $z$ coordinate) throughout the MD simulation time. Thus, positive distances to the closest water/lipid interface (averaged from the $z$ coordinates of its 64 phosphorus atoms) indicate that, at least, a fragment of the molecule is in the aqueous phase of the system, while negative values indicate that it is inside the POPC bilayer. The passive diffusion of the selected molecules throughout the MD runs is illustrated in Figures SC5-SC7, together with the total counting of hydrogen bonding interactions with chloride. Overall, regardless of the initial scenario, the associated chloride is promptly solvated and released to the water phase, typically within the first nanoseconds of each MD run. In the MD simulations in scenario $\mathcal{W}$, the molecules initially diffuse in the water phase of the system prior to permeating the bilayer. Despite the higher lipophilic character of the fluorinated aromatic ring (A) present in all molecules, this entity is not necessarily the first part of the molecule to permeate the membrane. However, as the molecules nested below the water/lipid interface and acquired their preferential orientations, the more lipophilic fluorinated ring A (red line in Figures SC4-SC6) is found deeper in the bilayer, and the $\mathbf{B}$ or $\mathbf{C}$ aromatic rings are positioned nearer to the water phase (blue and pink lines, respectively). This preferential relative position for $\mathbf{1}, \mathbf{3}, \mathbf{5 a}$ and $\mathbf{7}$, illustrated with MD snapshots in Figure 7 , was also achieved when the simulations were run with their chloride associations initially positioned within the POPC bilayer (scenario $\mathcal{P}$, see Figures SC4-SC6). Having observed the ergodicity between the spatial disposition relative to the water/lipid interface among individual stochastic MD runs, and regardless of the starting scenario, the MD sampling data (the last 80 or 130 ns of simulation time for scenarios $\mathcal{W}$ or $\mathcal{P}$, respectively) were merged, affording sampling periods of $0.63 \mu$ s $(\mathbf{1}, \mathbf{2}, \mathbf{5 c}, \mathbf{5 b}, \mathbf{7}$ and $\mathbf{1 9})$ or 1.89 us (3 and 5a). Therefore, the subsequent structural and energetic analyses of the 
unconstrained MD simulations were carried out with these merged data, except where otherwise stated.

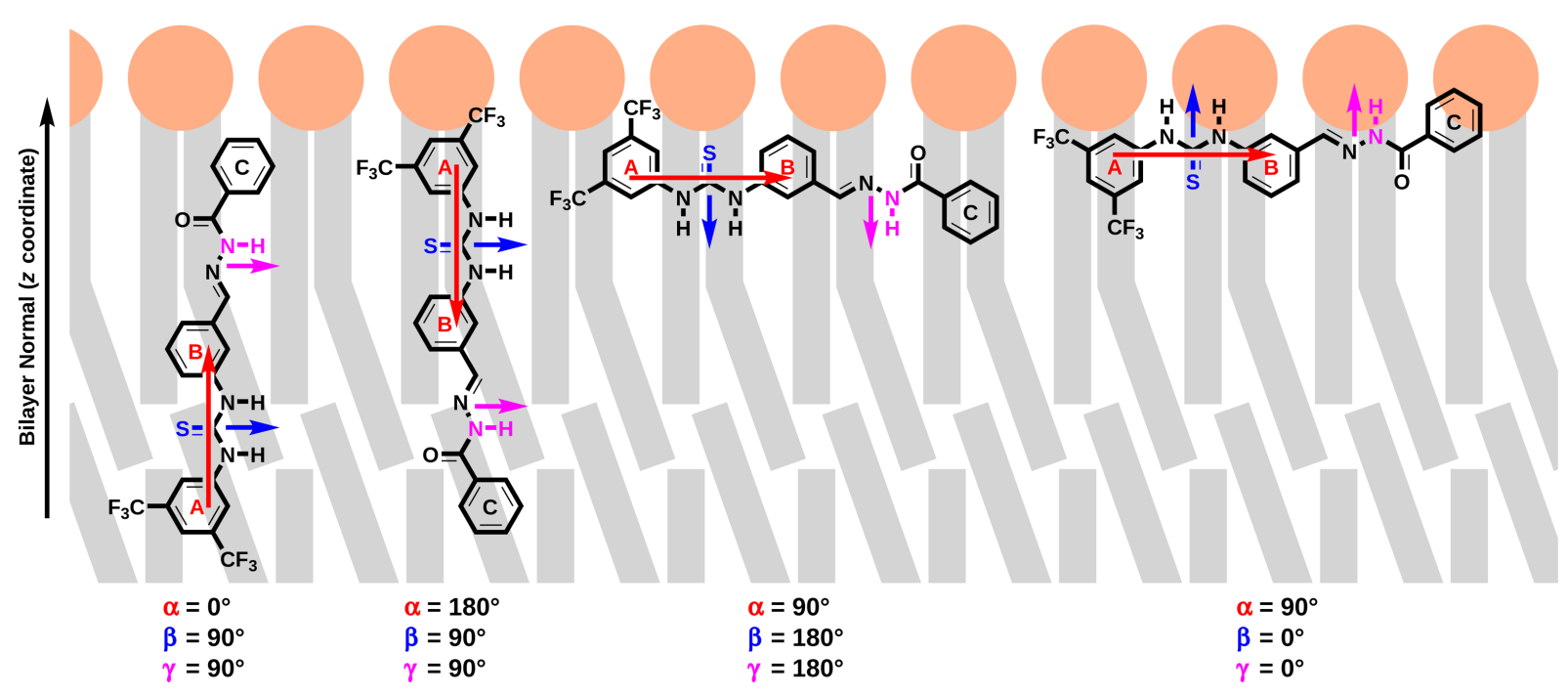

Figure 6. Schematic identification of the A, B and C reference points, illustrated for the aromatic rings of $\mathbf{5 a}$. The vectors $\overrightarrow{\boldsymbol{A B}}, \overrightarrow{S C}$ and $\overrightarrow{N H}$, used to assess the $\alpha, \beta$ and $\gamma$ angles with the bilayer normal are also illustrated for this molecule.

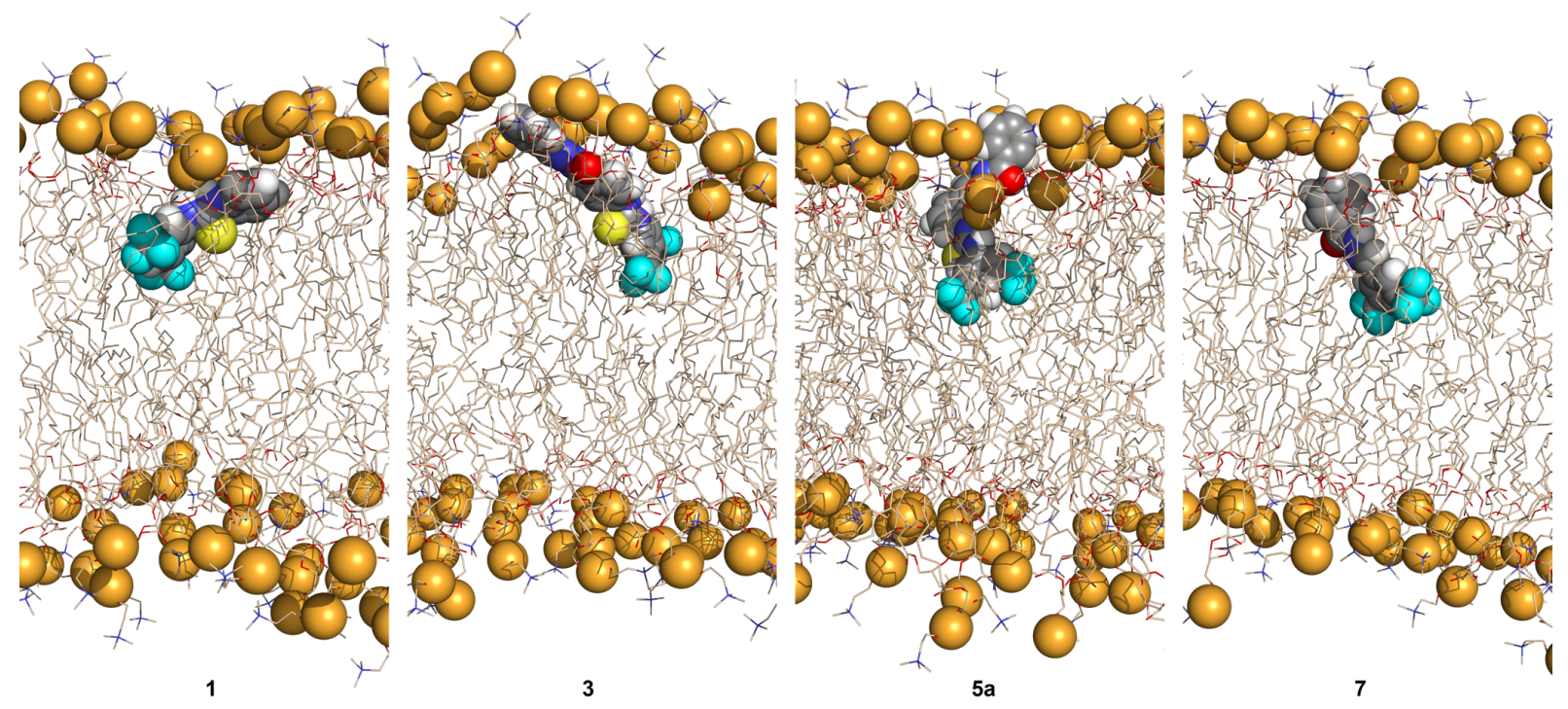

Figure 7. Snapshots of MD runs of transporters 1, 3, 5a, and 7, illustrating the orientations acquired at the water/lipid interface. Water molecules, aliphatic protons, and anions are omitted for clarity.

A more intuitive and complementary approach to ascertain the orientation of the different molecules towards the water/lipid interface is given by the $\alpha, \beta$ and $\gamma$ angles between the $\overrightarrow{\boldsymbol{A B}}$ (from the $\mathbf{A}$ to the $\mathbf{B}$ aromatic rings) $\overrightarrow{S C}$, (the thiourea $\mathrm{S}=\mathrm{C}$ bond) and $\overrightarrow{N H}$ (hydrazone $\mathrm{N}-\mathrm{H}$ bond) vectors, as defined in Figure 6 , and the $z$ coordinate. For instance, an angle $\alpha$ of $0^{\circ}$ is observed when an asymmetric receptor is parallel to the $z$ coordinate with the fluorinated $\mathbf{A}$ ring found deeper in the bilayer, while a $180^{\circ}$ angle indicates that this ring is closer to the interface. $A 90^{\circ} \alpha$ angle corresponds to an intermediate orientation, with the molecule parallel to the interface. The $\beta$ and $\gamma$ angles give the orientation of the binding motifs, towards the water phase $\left(\sim 0^{\circ}\right)$ or to the bilayer core $\left(\sim 180^{\circ}\right)$. The histograms for the $\alpha, \beta$ and $\gamma$ angle values are plotted in Figures SC7-SC 8 , while their average values with standard deviations are listed in Table SC4.

The average $\alpha$ angle values of $58.9 \pm 21.8^{\circ}$ and $62.3 \pm 21.1^{\circ}$ for 1 and 2 , respectively, indicate that these mono-thioureas often adopt tilted spatial dispositions while their thiourea binding units are frequently found pointing to the water phase, enabling them to interact with phospholipid 
headgroups, water molecules or solvated chloride ions, as detailed below. An equivalent dynamic behaviour was experienced by the $\mathrm{N}, \mathrm{N}$-dimethyl-hydrazone derivative $\mathbf{5 c}$ in the POPC bilayer, as given by the identical distribution profiles of the $\alpha$ and $\beta$ angles, with average values of $68.3 \pm 21.5^{\circ}$ and $44.4 \pm 23.1^{\circ}$, respectively. Moreover, in the MD runs of acylhydrazone derivatives $\mathbf{3}$ and $\mathbf{5 a}$, the aromatically flanked thiourea fragments are spatially oriented in the membrane system similarly to 1, 2 and $5 c$, as indicated by the similarity between the corresponding $\alpha$ and $\beta$ angles. However, the $\gamma$ angle values of the acylhydrazone fragment of $5 \mathrm{a}$, spanning between 0 and $180^{\circ}$, lead to an average value with a larger standard deviation of $77.1 \pm 41.4^{\circ}$. On the other hand, the distribution profile for 3 presents two distinct local maxima (see Figure SC7) around 38 and $113^{\circ}$. In other words, the orientation of the acylhydrazone binding unit is typically variable, allowing it to easily interact, mainly through the $\mathrm{NH}$ binding unit (vide infra), with the phosphate headgroups, water molecules as well as with the ester groups of the $s n-1$ and $s n-2$ phospholipid chains. In stark contrast, the phenylhydrazone $\mathbf{5 b}$ shows a narrower variation of the $\gamma$ angle, averaging $38.7 \pm 25.3^{\circ}$, which suggests a clearly oriented $\mathrm{NH}$ binding unit, always pointing to the water phase. Noteworthy, the acylhydrazone's NH units in $\mathbf{3}$ and $\mathbf{5 a}$ have higher $V_{s, \max }$ values than $\mathbf{5 b}$ (Table 1 ), having a higher propensity to swap between different hydrogen bonding acceptors at the water/lipid interface, consequently forcing the acylhydrazone to assume variable orientations relative to the $z$ coordinate. Still, the variations in $\alpha$ and $\gamma$ angles for 7 (Figure SC8) show that it is possible for a single acylhydrazone-based receptor to be clearly oriented at the water/lipid interface with respective $\alpha$ and $\gamma$ angle average values of $63.2 \pm 21.3^{\circ}$ and $38.7 \pm 25.3^{\circ}$. The bis-thiourea 19 displays well-defined $\alpha$ and $\beta$ angle profiles for both thiourea binding moieties and their corresponding average values compare well with the ones calculated for the remaining receptors, namely the mono-thiourea 1, 2 and $\mathbf{5 c}$. Moreover, the overlapping between the $\alpha$ and $\beta$ profiles calculated for each thiourea binding unit indicates that they are indistinguishable, being equally able to independently recognise chloride ions, water molecules or phospholipid headgroups, at the water/lipid interface level.

The hydrogen bonding contacts from the thiourea or hydrazone-based binding motifs to water molecules, chloride ions and phospholipids were evaluated throughout the entire simulation time of the different replicates carried out for each receptor. The total number of these hydrogen bonds as a function of the $z$ coordinate are plotted in Figure 8 for $\mathbf{1}$ and $\mathbf{3}$ and in Figure SC9 and SC10 for the remaining receptors. Overall, along the diffusion in the water phase (scenario $\mathcal{W}$, positive values of $z$ ) the thiourea binding unit of $\mathbf{1}, \mathbf{2}, \mathbf{3}, \mathbf{5 a}, \mathbf{5 b}$, and $\mathbf{5 c}$ occasionally recognises one of the eighteen solvated chloride ions. On the other hand, when these molecules are putatively inserted into the bilayer core (scenario $\mathcal{P}$, negative values of $z$ ), the chloride hydrogen bonded to the thiourea binding unit is promptly hydrated, being released to the water phase. Afterwards, the chloride uptake events become sporadic, as given by the number of $\mathrm{N}-\mathrm{H} \cdots \mathrm{Cl}^{-}$close to zero. Regardless of the $\mathcal{W}$ or $\mathcal{P}$ starting scenarios, as the receptors reach the water lipid interface $(z=0$ $\AA)$, the hydrogen bonds between the two thiourea NH binding units and the water molecules are partially replaced by interactions with phospholipids, mainly with the phosphate headgroups and with the $s n-1$ and $s n-2$ ester groups (to a smaller extent), in agreement with the orientation and location of each receptor below the water/lipid interface. The total number of hydrogen bonds between 19 and the phospholipids naturally increases due to the existence of two independent thiourea binding motifs. Moreover, they were found to be able to bind two phosphate headgroups simultaneously by several times throughout the MD runs, as illustrated in Figure 9. Thus, the superior binding affinity of this bis-thiourea for phospholipids is probably linked with its inability to promote the chloride transmembrane efflux. 

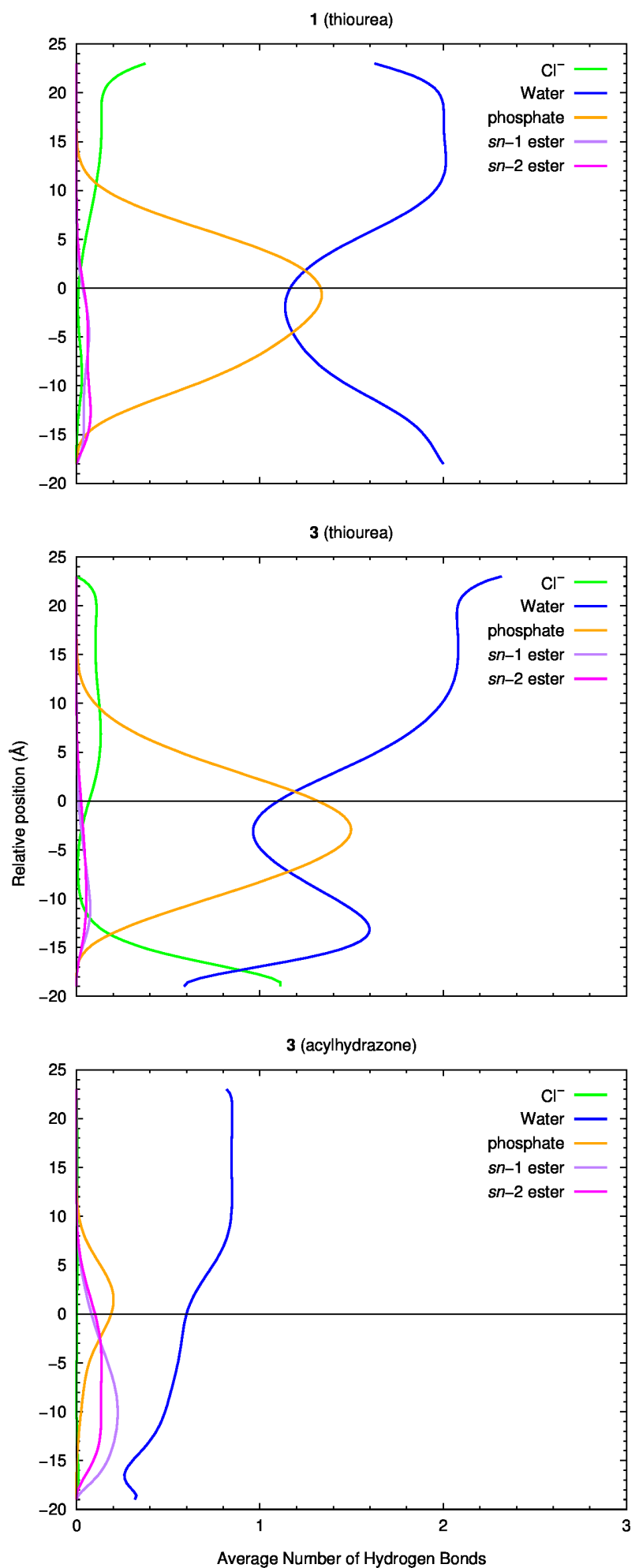

Figure 8. Average number of thiourea hydrogen bonds vs the relative position of the centre of mass of $\mathbf{1}$ (top) and $\mathbf{3}$ (middle), or of the acylhydrazone binding motif of $\mathbf{3}$ (bottom). The following colour scheme is used for the interactions with the chloride ions (green), water molecules (blue), POPC head groups (orange), and ester groups (magenta for the $s n-1$ chains and purple for the $s n-2$ chains). The water/lipid interface is represented as a black line at $z=0 \AA$. Data were smoothened using Bézier curves. 


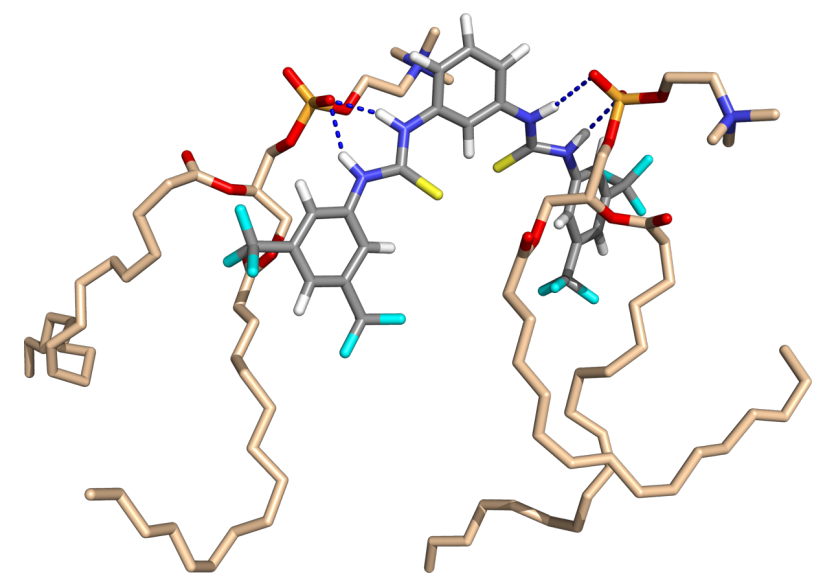

Figure 9. MD snapshot illustrating the interaction of two thiourea binding units of $\mathbf{1 9}$ with two POPC phosphate head groups.

Beyond the hydrogen bonds with water molecules, the hydrazone binding units of $\mathbf{3}$ and $\mathbf{5 a}$ swap between the phosphate, $s n-1$ and $s n-2$ ester phospholipid groups, establishing intermittent N$\mathrm{H} \cdots \mathrm{O}$ hydrogen bonds, putatively assisted by $\mathrm{C}-\mathrm{H} \cdots \mathrm{O}$ bonding contacts, in line with the wide range of $\gamma$ angle values and the $V_{\mathrm{S}}$ values in these binding motifs. In addition, $\mathbf{5 b}$ and $\mathbf{7}$ also present an equivalent pattern of hydrogen bonding interactions, although the hydrazone binding motif's orientation of these molecules is more defined, as shown by the narrower variation of the corresponding $\gamma$ angles (see Table SC4) In spite of the small extent of these hydrogen bonds, they have a significant impact on the interaction of these hydrazone-based receptors with the POPC membrane model as shown by the following energy calculations.

The interaction between the phospholipids of POPC membrane model and the compounds $1,2,3,5 a, 5 b, 5 c, 7$ and 19 was evaluated from the unrestrained passive diffusion MD simulations reported above using their last $50 \mathrm{~ns}$, via molecular mechanics (MM) gas-phase interaction energies. The contributions of the non-bonded electrostatic ( $\left.\Delta E_{\text {elec }}\right)$ and van der Waals ( $\left.\Delta E_{\mathrm{vdw}}\right)$ energy terms to the total $M M$ interaction energy $\left(\Delta E_{\mathrm{MM}}\right)$ were calculated as detailed in $\mathrm{ESI}$, and their average values obtained for the total sampling time of each simulated molecule are listed in Table SC3, together with the experimental transport activities reported in Figure S35. The magnitude of $\Delta E_{\mathrm{MM}}$ values almost linearly increases with the $\Delta E_{\text {elec }}\left(R^{2}=0.93\right)$ and $\Delta E_{\mathrm{vdw}}\left(R^{2}=0.93\right)$ values, with the last ones being the main contributor to the $\Delta E_{\mathrm{MM}}$ values. The smaller molecules $\mathbf{1}$ and $\mathbf{2}$ with $\Delta E_{\mathrm{vdW}}$ values of -40.9 and $-46.4 \mathrm{kcal} \mathrm{mol}^{-1}$ are good transporters, followed by $5 \mathrm{c}$, with $\Delta E_{\mathrm{vdw}}$ value of -51.6 $\mathrm{kcal} \mathrm{mol}^{-1}$, which is a moderate transporter. Larger receptors $\mathbf{3}, \mathbf{5} \mathbf{a}$ and $\mathbf{5 b}$, containing hydrazone motifs with equivalent lengths, present $\Delta E_{\mathrm{vdw}}$ values around $58 \mathrm{kcal} \mathrm{mol}^{-1}$ and are poor transporters. The ability to promote the chloride efflux also drops as the electrostatic interactions with the bilayer become stronger. Thus, $\mathbf{1}, \mathbf{2}$ and $\mathbf{5 c}$, with a single thiourea binding motif, show comparable $\Delta \mathrm{E}_{\text {elec }}$ average values, being good and moderate transporters, respectively. On the other hand, the binding ability of the acylhydrazone binding unit of $\mathbf{5 a}$ and $\mathbf{3}$ (assessed with $V_{s}$, see Table 1 ) gradually leads to increasingly stronger electrostatic interactions with the bilayer ( $\left.c a .-28.6 \mathrm{kcal} \mathrm{mol}^{-1}\right)$, contributing to their poorer transport ability. The meta-phenylene bis-thiourea 19, with two highly lipophilic and electron-withdrawing 3,5-bis(trifluoromethyl)phenyl groups is a poor transporter, presenting the highest values for the $\Delta E_{\text {elec }}$ and $\Delta E_{\mathrm{vdw}}$ terms of $-35.2 \pm 15.6$ and $-67.1 \pm 4.2 \mathrm{kcal} \mathrm{mol}^{-1}$, respectively. Indeed, this is the molecule with the most acidic $\mathrm{NH}$ binding sites, as shown by their $V_{\mathrm{s} \text {, max }}$ values of $100.3 \mathrm{kcal} \mathrm{mol}^{-1}$. On the other hand, 7 with $\Delta E_{\text {elec }}$ and $\Delta E_{\mathrm{vdw}}$ values of $-8.0 \pm 5.3$ and $-41.7 \pm 3.3 \mathrm{kcal}$ $\mathrm{mol}^{-1}$, interacts weakly with the bilayer and is a poor transporter. However, 7 only has an acylhydrazone binding unit, with a low chloride affinity, as shown by DFT calculations and ${ }^{1} \mathrm{H}$ NMR titration binding data. Overall, the $\Delta E_{\mathrm{MM}}$ values of the mono-thiourea derivatives are related with their experimental transport activities, as illustrated in Figure 10. 


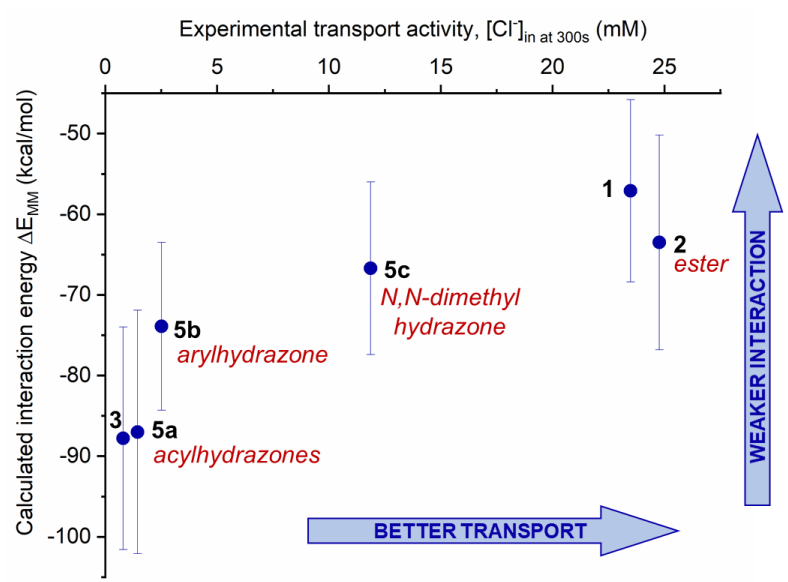

Figure 10. Relation between the total $\Delta E_{M M}$ interaction energies calculated for compounds $\mathbf{1}, \mathbf{2}, \mathbf{3}, \mathbf{5 a}, \mathbf{5 b}$ and $\mathbf{5 c}$ and their experimental transport activities, defined as the concentration of chloride transported into the vesicles after 300 s of transport.

\section{Conclusions}

Our results indicate that hydrazone groups present in the structure of an anion receptor can have unexpected effects on the transport properties. Functionalization of thiourea transport moieties, in meta or para position, with aryl- and acylhydrazone groups yielded compounds $\mathbf{3}, \mathbf{5 a}$ and $\mathbf{5 b}$, which showed a transport activity dramatically lower than that of reference thiourea $\mathbf{1}$. Our studies indicate that such a negative effect on transport activity cannot originate from differences in the chloride binding affinity of the molecules. Instead, the poor transport appears to be caused by the presence of acidic NHs in the hydrazone groups, which probably act as a second anion binding site able to interact with the phospholipid head groups. To support this hypothesis, we have shown that meta-phenylene bis(thio)ureas 18 and 19, with two anion binding motifs that cannot bind the same anion, have a much lower transport activity compared to mono(thio)ureas $\mathbf{1}$ and $\mathbf{1 6}$ and orthophenylene bisurea 17. This suggests that the effect of separate binding sites is not specific for hydrazone groups, but applies also for ureas and thioureas, and probably for other anion binding motifs.

MD simulations on the most relevant compounds in a POPC membrane model showed that the molecules diffuse to the water/lipid interface, where they are oriented with the more lipophilic fluorinated ring deeper in the bilayer and the other aromatic rings closer to the water phase. The thiourea groups were frequently found with the $\mathrm{NH}$ binding units pointing to the water phase and interacting with water molecules and the phospholipid head groups. In the case of the acylhydrazones binding motifs, their orientations were more variable and showed interactions with water molecules, as well as with the phosphate and ester groups of the phospholipids. Furthermore, a clear relationship was observed between the $\mathrm{MM}$ interaction energies and the transport activity of the different thioureas. The molecules having the strongest interactions with the phospholipids are those with the lowest transport activities, while the best transporters were found to have the lowest interaction energies with the POPC bilayer.

These computational results support the hypothesis presented in Figure 4, in which the negative effect of a second anion binding site on the transport activity of a thiourea moiety was attributed to the additional interactions with the membrane phospholipids. We also note that hydrogen bond acceptor groups were found to have a negative impact on the transport, albeit less than the hydrogen bond donors. Furthermore, commonly used calculated logP values cannot predict the interaction of transporters with the membrane, as both polar groups, such as acylhydrazones, (electrostatic interactions) and apolar phenyl groups (van der Waals interactions) contribute to the total interaction energy. This study shows that the introduction of additional functional groups in transmembrane transporters can come at great cost for the transport activity, 
which should be considered when designing new transporters that rely on diffusion of the compounds and complexes across the membrane.

\section{Acknowledgments}

The results reported here are part of a project that has received funding from the European Research Council (ERC) under the European Union's Horizon 2020 research and innovation programme (Grant agreement No. 802727). HV is a research associate of the Fonds de la Recherche Scientifique - FNRS. The computational studies were funded within the scope of the project CICECOAveiro Institute of Materials, UIDP/50011/2020, financed by national funds through the Portuguese Foundation for Science and Technology/MCTES.

\section{References}

\footnotetext{
${ }^{1}$ D. C. Gadsby, Nat. Rev. Mol. Cell Biol., 2009, 10, 344.

2 F. M. Ashcroft, Nature, 2006, 440, 440-447.

${ }^{3}$ J. T. Davis, P. A. Gale and R. Quesada, Chem. Soc. Rev., 2020, 49, 6056-6086.

${ }^{4}$ P. A. Gale, J. T. Davis and R. Quesada, Chem. Soc. Rev., 2017, 46, 2497-2519.

${ }^{5}$ S.-P. Zheng, L.-B. Huang, Z. Sun and M. Barboiu, Angew. Chem. Int. Ed., 2021, 60, 566-597.

${ }^{6}$ N. Busschaert, I. L. Kirby, S. Young, S. J. Coles, P. N. Horton, M. E. Light and P. A. Gale, Angew. Chem. Int. Ed., 2012, 51, 4426-4430.

${ }^{7}$ M. J. Spooner and P. A. Gale, Chem. Commun., 2015, 51, 4883-4886.

${ }^{8}$ H. Valkenier, C. J. E. Haynes, J. Herniman, P. A. Gale and A. P. Davis, Chem. Sci., 2014, 5, 1128-1134.

${ }^{9}$ V. Saggiomo, S. Otto, I. Marques, V. Felix, T. Torroba and R. Quesada, Chem. Commun., 2012, 48, 52745276.

${ }^{10}$ X. Wu, J. R. Small, A. Cataldo, A. M. Withecombe, P. Turner and P. A. Gale, Angew. Chem. Int. Ed., 2019, 58, 15142-15147.

${ }^{11}$ C. M. Dias, H. Valkenier and A. P. Davis, Chem. Eur. J., 2018, 24, 6262-6268.

12 H. Valkenier, L. W. Judd, H. Li, S. Hussain, D. N. Sheppard and A. P. Davis, J. Am. Chem. Soc., 2014, 136, 12507-12512.

${ }^{13}$ S.-K. Ko, S. K. Kim, A. Share, V. M. Lynch, J. Park, W. Namkung, W. Van Rossom, N. Busschaert, P. A. Gale, J. L. Sessler and I. Shin, Nat. Chem., 2014, 6, 885-892.

${ }^{14}$ P. Iglesias Hernandez, D. Moreno, A. Araujo Javier, T. Torroba, R. Perez-Tomas and R. Quesada, Chem. Commun., 2012, 48, 1556-1558.

${ }^{15}$ G. Picci, I. Carreira-Barral, D. Alonso-Carrillo, D. Sanz-González, P. Fernández-López, M. García-Valverde, C. Caltagirone and R. Quesada, Supramol. Chem., 2020, 32, 112-118.

${ }^{16}$ K. M. Bąk, K. Chabuda, H. Montes, R. Quesada and M. J. Chmielewski, Org. Biomol. Chem., 2018, 16, 5188-5196.

${ }^{17}$ S. V. Shinde and P. Talukdar, Chem. Commun., 2018, 54, 10351-10354.

${ }^{18}$ P. Vieira, M. Q. Miranda, I. Marques, S. Carvalho, L.-J. Chen, E. N. W. Howe, C. Zhen, C. Y. Leung, M. J. Spooner, B. Morgado, O. A. B. da Cruz e Silva, C. Moiteiro, P. A. Gale and V. Félix, Chem. Eur. J., 2020, 26, 888-899.

19 J. Li, P. Nowak and S. Otto, J. Am. Chem. Soc., 2013, 135, 9222-9239.

${ }^{20}$ S. R. Beeren and J. K. M. Sanders, J. Am. Chem. Soc., 2011, 133, 3804-3807.

${ }^{21}$ P. T. Corbett, J. Leclaire, L. Vial, K. R. West, J.-L. Wietor, J. K. M. Sanders and S. Otto, Chem. Rev., 2006, 106, 3652-3711.

${ }^{22}$ B. Shao and I. Aprahamian, Chem, 2020, 6, 2162-2173.

${ }^{23}$ Z. Kokan and M. J. Chmielewski, J. Am. Chem. Soc., 2018, 140, 16010-16014.

${ }^{24}$ G. Vantomme, S. Jiang and J.-M. Lehn, J. Am. Chem. Soc., 2014, 136, 9509-9518.

${ }^{25}$ E. N. W. Howe, N. Busschaert, X. Wu, S. N. Berry, J. Ho, M. E. Light, D. D. Czech, H. A. Klein, J. A. Kitchen and P. A. Gale, J. Am. Chem. Soc., 2016, 138, 8301-8308.

${ }^{26}$ Y. Zhou, Y. Chen, P.-P. Zhu, W. Si, J.-L. Hou and Y. Liu, Chem. Commun., 2017, 53, 3681-3684.
} 
${ }^{27}$ S. Das, N. Rawat and T. K. Panda, ChemistrySelect, 2020, 5, 476-479.

${ }^{28}$ D. Brynn Hibbert and P. Thordarson, Chem. Commun., 2016, 52, 12792-12805.

${ }^{29}$ Gaussian 16, Revision C.01, Frisch, M. J.; Trucks, G. W.; Schlegel, H. B.; Scuseria, G. E.; Robb, M. A.; Cheeseman, J. R.; Scalmani, G.; Barone, V.; Petersson, G. A.; Nakatsuji, H.; Li, X.; Caricato, M.; Marenich, A. V.; Bloino, J.; Janesko, B. G.; Gomperts, R.; Mennucci, B.; Hratchian, H. P.; Ortiz, J. V.; Izmaylov, A. F.; Sonnenberg, J. L.; Williams-Young, D.; Ding, F.; Lipparini, F.; Egidi, F.; Goings, J.; Peng, B.; Petrone, A.; Henderson, T.; Ranasinghe, D.; Zakrzewski, V. G.; Gao, J.; Rega, N.; Zheng, G.; Liang, W.; Hada, M.; Ehara, M.; Toyota, K.; Fukuda, R.; Hasegawa, J.; Ishida, M.; Nakajima, T.; Honda, Y.; Kitao, O.; Nakai, H.; Vreven, T.; Throssell, K.; Montgomery, J. A., Jr.; Peralta, J. E.; Ogliaro, F.; Bearpark, M. J.; Heyd, J. J.; Brothers, E. N.; Kudin, K. N.; Staroverov, V. N.; Keith, T. A.; Kobayashi, R.; Normand, J.; Raghavachari, K.; Rendell, A. P.; Burant, J. C.; Iyengar, S. S.; Tomasi, J.; Cossi, M.; Millam, J. M.; Klene, M.; Adamo, C.; Cammi, R.; Ochterski, J. W.; Martin, R. L.; Morokuma, K.; Farkas, O.; Foresman, J. B.; Fox, D. J. Gaussian, Inc., Wallingford CT, 2019. ${ }^{30}$ S. Grimme, J. Antony, S. Ehrlich and H. Krieg, J. Chem. Phys., 2010, 132, 154104.

${ }^{31}$ V. Barone and M. Cossi, J. Phys. Chem. A, 1998, 102, 1995-2001.

${ }^{32}$ M. Cossi, N. Rega, G. Scalmani and V. Barone, J. Comput. Chem., 2003, 24, 669-681.

${ }^{33}$ C. M. Dias, H. Li, H. Valkenier, L. E. Karagiannidis, P. A. Gale, D. N. Sheppard and A. P. Davis, Org. Biomol. Chem., 2018, 16, 1083-1087.

${ }^{34}$ L. Martínez-Crespo, J. L. Sun-Wang, P. Ferreira, C. F. M. Mirabella, G. Aragay and P. Ballester, Chem. Eur. J., 2019, 25, 4775-4781.

35 J. M. Boon, T. N. Lambert, B. D. Smith, A. M. Beatty, V. Ugrinova and S. N. Brown, J. Org. Chem., 2002, 67, 2168-2174.

${ }^{36}$ S. J. Moore, C. J. E. Haynes, J. González, J. L. Sutton, S. J. Brooks, M. E. Light, J. Herniman, G. J. Langley, V. Soto-Cerrato, R. Pérez-Tomás, I. Marques, P. J. Costa, V. Félix and P. A. Gale, Chem. Sci., 2013, 4, 103-117.

${ }^{37}$ S. J. Edwards, I. Marques, C. M. Dias, R. A. Tromans, N. R. Lees, V. Félix, H. Valkenier and A. P. Davis, Chem. Eur. J., 2016, 22, 2004-2011.

${ }^{38}$ I. Marques, P. M. R. Costa, M. Q. Miranda, N. Busschaert, E. N. W. Howe, H. J. Clarke, C. J. E. Haynes, I. L. Kirby, A. M. Rodilla, R. Pérez-Tomás, P. A. Gale and V. Félix, PCCP, 2018, 20, 20796-20811.

${ }^{39}$ A. Roy, O. Biswas and P. Talukdar, Chem. Commun., 2017, 53, 3122-3125.

${ }^{40}$ A. Saha, N. Akhtar, V. Kumar, S. Kumar, H. K. Srivastava, S. Kumar and D. Manna, Org. Biomol. Chem., 2019, 17, 5779-5788.

${ }^{41}$ A. Kerckhoffs and M. J. Langton, Chem. Sci., 2020, 11, 6325-6331.

${ }^{42}$ Y. R. Choi, G. C. Kim, H.-G. Jeon, J. Park, W. Namkung and K.-S. Jeong, Chem. Commun., 2014, 50, 1530515308.

${ }^{43}$ N. Busschaert, S. J. Bradberry, M. Wenzel, C. J. E. Haynes, J. R. Hiscock, I. L. Kirby, L. E. Karagiannidis, S. J. Moore, N. J. Wells, J. Herniman, G. J. Langley, P. N. Horton, M. E. Light, I. Marques, P. J. Costa, V. Félix, J. G. Frey and P. A. Gale, Chem. Sci., 2013, 4, 3036-3045.

${ }^{44}$ B. A. McNally, A. V. Koulov, T. N. Lambert, B. D. Smith, J.-B. Joos, A. L. Sisson, J. P. Clare, V. Sgarlata, L. W. Judd, G. Magro and A. P. Davis, Chem. Eur. J., 2008, 14, 9599-9606.

${ }^{45}$ I. R. Gould, S. A.A., C. J. Dickson, B. D. Madej and R. C. Walker, 2018. Lipid17: A comprehensive AMBER force field for the simulation of zwitterionic and anionic lipids.

${ }^{46}$ W. L. Jorgensen, J. Chandrasekhar, J. D. Madura, R. W. Impey and M. L. Klein, J. Chem. Phys., 1983, 79, 926-935.

${ }^{47}$ P. Li, L. F. Song and K. M. Merz, Jr., J Chem Theory Comput, 2015, 11, 1645-1657.

48 J. Wang, R. M. Wolf, J. W. Caldwell, P. A. Kollman and D. A. Case, J. Comput. Chem., 2004, 25, 1157-1174.

${ }^{49}$ C. I. Bayly, P. Cieplak, W. Cornell and P. A. Kollman, J. Phys. Chem., 1993, 97, 10269-10280.

${ }^{50}$ D.A. Case, I.Y. Ben-Shalom, S.R. Brozell, D.S. Cerutti, T.E. Cheatham, III, V.W.D. Cruzeiro, T.A. Darden, R.E. Duke, D. Ghoreishi, G. Giambasu, T. Giese, M.K. Gilson, H. Gohlke, A.W. Goetz, D. Greene, R Harris, N. Homeyer, Y. Huang, S. Izadi, A. Kovalenko, R. Krasny, T. Kurtzman, T.S. Lee, S. LeGrand, P. Li, C. Lin, J. Liu, T. Luchko, R. Luo, V. Man, D.J. Mermelstein, K.M. Merz, Y. Miao, G. Monard, C. Nguyen, H. Nguyen, A. Onufriev, F. Pan, R. Qi, D.R. Roe, A. Roitberg, C. Sagui, S. Schott-Verdugo, J. Shen, C.L. Simmerling, J. Smith, J. Swails, R.C. Walker, J. Wang, H. Wei, L. Wilson, R.M. Wolf, X. Wu, L. Xiao, Y. Xiong, D.M. York and P.A. Kollman (2019), AMBER 2019, University of California, San Francisco.

${ }^{51}$ R. Salomon-Ferrer, A. W. Gotz, D. Poole, S. Le Grand and R. C. Walker, J Chem Theory Comput, 2013, 9, 3878-3888.

${ }^{52}$ S. Le Grand, A. W. Götz and R. C. Walker, Comput. Phys. Commun., 2013, 184, 374-380. 